Final Technical Report

\title{
Reduction of Oxidative Melt Loss \\ Of Aluminum and Its Alloys \\ DE-FC36-00ID13898
}

February 2006

Principal Investigator:

Dr. Subodh K. Das

Secat, Inc.

1505 Bull Lea Road

Lexington, KY 40511 


\section{Final Technical Report}

Project Title: $\quad$ Reduction of Oxidative Melt Loss of Aluminum and Its Alloys

Project Period: $\quad$ April 12, 2000 to December 31, 2004

DOE Award No: $\quad$ DE-FC36-00ID13898

Award Recipient: $\quad$ Secat, Inc.

Principal Investigator: $\quad$ Dr. Subodh K. Das (Secat, Inc)

Additional Researchers: Dr. John Hryn (Argonne)

Mr. Greg Krumdick (Argonne)

Dr. Peter Tortorelli (ORNL)

Dr. Karren More (ORNL)

Mr. John Clark (ARC)

Mr. Shridas Ningileri (Secat)

Dr. David A Atwood

National Laboratories: Albany Research Center

Argonne National Laboratory

Oak Ridge National Laboratory

Universities: $\quad$ University of Kentucky

Industry Partners: Alcan Aluminum Corp.

ARCO Aluminum, Inc.

NSA Division of Southwire

(Now Century Aluminum of Kentucky)

Commonwealth Aluminum

(Now Aleris International)

Hydro Aluminum Louisville, Inc.

IMCO Recycling, Inc.

(Now Aleris International)

Logan Aluminum, Inc.

McCook Metals, LLC

(No longer in existence) 


\section{Reduction of Oxidative Melt Loss of Aluminum and Its Alloys}

DE-FC36-00ID13898

Contributors to this report include:

John Clark, Albany Research Center

John Hryn, Argonne National Laboratory

Greg Krumdick, Argonne National Laboratory

Karren More, Oak Ridge National Laboratory

Peter Tortorelli, Oak Ridge National Laboratory

David A Atwood University of Kentucky

Shridas Ningileri, Secat Inc

February 2006

This Report was prepared by John Hryn - Argonne National Laboratory 9700 South Cass Avenue

Argonne, IL 60439-481

Shridas Ningileri - Secat Inc

1505 Bull Lea Road

Lexington, KY 40513 


\section{Acknowledgments and Disclaimer}

\section{Acknowledgments}

This report is based upon work supported by the U.S. Department of Energy, Energy Efficiency and Renewable Energy, Industrial Technologies Program, Aluminum Industry of the Future, under Solicitation No. DE-PS07-99ID13824 with award made to Secat, Inc.

Research was sponsored and supported by the U.S. Department of Energy under Award No.

DE-FC36-00ID13898

The significant accomplishments of this project would not have been achieved without access to the excellent facilities of the Argonne National Laboratory, Oak Ridge National Laboratory, Albany Research Center and University of Kentucky made available through Peter Angelini, H. Wayne Hayden, John Hryn, John Clark, David A Atwood and S.K. Das besides the in kind support of time, materials and sample collections from various facilities of the industrial partners participating in this project. The principal investigators of this project also realize that the significant accomplishments of this endeavor could not have been achieved except through the dedicated and excellent contributions of the project research team members from the Argonne National Lab, Oak Ridge National Laboratory, the University of Kentucky, the Albany Research Center, and Secat, comprised of John Clark, John Hryn, Greg Krumdick, Karren More, David A Atwood and Shridas Ningileri.

\section{Disclaimer}

This report was prepared as an account of work sponsored by an agency of the United States Government. Neither the United States Government nor any agency thereof, nor any of their employees, makes any warranty, express or implied, or assumes any legal liability or responsibility for the accuracy, completeness, or usefulness of any information, apparatus, product, or process disclosed, or represents that its use would not infringe privately owned rights. References herein to any specific commercial product, process, or service by trade name, trademark, manufacturer, or otherwise, does not necessarily constitute or imply its endorsement, recommendation, or favoring by the United State Government or any agency thereof. The views and opinions of authors expressed herein do not necessarily state or reflect those of the United States Government or any agency thereof. 


\section{Table of Contents}

$\begin{array}{ll}\text { Table of Contents } & 5\end{array}$

$\begin{array}{ll}\text { List of Tables and Figures } & 7\end{array}$

$\begin{array}{lr}\text { Abbreviations and Acronyms } & 8\end{array}$

1. Executive Summary 9

1.1 Research and Development 9

1.2 Technology Transfer 11

1.3 Commercialization $\quad 11$

$\begin{array}{ll}1.4 \text { Recommendations } & 11\end{array}$

2. Introduction 12

3. Background 14

3.1 Project Goals and Scope $\quad 14$

3.2 Statement of Objectives $\quad 14$

3.3 Work Breakdown Structure $\quad 15$

4. Microstructural Evaluation of Industrial Dross 17

$\begin{array}{ll}4.1 \text { Introduction } & 17\end{array}$

4.2 Experimental Procedure 17

4.3 Results and Discussion $\quad 20$

4.3.1 Alloy 1350 (no Mg) $\quad 20$

4.3.2 Alloy 3004 (low Mg) 23

4.3.3 Alloy 5182 (high Mg) 27

4.3.4 Oxidation Sequence and Time to Breakaway 29

$\begin{array}{ll}\text { 4.4 Summary } & 30\end{array}$

5. Analyses of Molten Aluminum Alloy Surfaces

5.1 Introduction $\quad 31$

5.2 X-ray Photoelectron Spectroscopy 31

5.3 X-ray Diffraction 32

5.4 Experimental $\quad 32$

5.5 Results 33

5.6 Summary $\quad 34$

6. Laboratory-Scale Reverberatory Furnace $\quad 35$

6.1 Introduction $\quad 35$

6.2 Furnace Characteristics $\quad 35$

6.3 Dross Formation $\quad 35$ 
7. Development and Evaluation of Melt Loss Reduction Technology 39

7.1 Introduction $\quad 39$

7.2 Materials Compatibility Studies $\quad \mathbf{4 0}$

7.3 Experimental Studies - Argonne $\quad 41$

7.4 Experimental Studies - ARC reverberatory $\quad 44$

$\begin{array}{ll}7.5 \text { Summary } & 45\end{array}$

8. Accomplishments $\quad 46$

8.1 Technical Accomplishments $\quad 46$

$\begin{array}{ll}\text { 8.2 Technology Transfer } & 47\end{array}$

8.3 Commercialization $\quad 48$

8.4 Publications and Presentations 48

$\begin{array}{ll}\text { 9. Summary and Conclusions } & 49\end{array}$

10. Recommendations 49

$\begin{array}{ll}\text { 11. References } & 50\end{array}$ 


\section{List of Tables and Figures}

Table 4.1 Compositions of Al alloys from metal button analysis

Table 7.2 Candidate protective barrier material properties

Table 7.2 Summary of primary compatibility study of protective barriers

Fig 4.1 Bulk dross sample $(\sim 10-15 \mathrm{~cm}$ diameter at surface and $10 \mathrm{~cm}$ deep $)$ after cooling and removing from crucible

Fig 4.2 Cross-section of bulk dross sample showing the dross layer at the surface

Fig 4.3 BSE image showing layered structure (denoted by arrows) in an oxide-rich region in dross collected from molten 1350

Fig 4.4 High magnification BSE image of area within box in Figure 3 showing 3-layer structure in dross collected from molten 1350

Fig 4.5 Elemental maps for Al, O, N, and Ti from same region shown in Figure 4

Fig 4.6 BSE image showing layered structure in an oxide-rich region in dross collected from molten alloy 1350 .

Fig 4.7 Computed equilibrium diagram for the $\mathrm{Al} / \mathrm{Al}_{2} \mathrm{O}_{3} / \mathrm{AlN}$ system at $700^{\circ} \mathrm{C}$ and low $p\left(\mathrm{O}_{2}\right)$ and $p\left(\mathrm{~N}_{2}\right)$

Fig 4.8 Dross particle from surface of molten 3004 \#1 (arrows denote trapped Al metal).

Fig 4.9 BSE image showing distribution of three phases, $a-\mathrm{Al}_{2} \mathrm{O}_{3}$ (shown by arrows), $\mathrm{MgO}$, and $\mathrm{MgAl}_{2} \mathrm{O}_{4}$ identified in dross from $3004 \# 1$

Fig 4.10 BSE image showing fragmented oxide particles within dross layer collected from 3004 \#2

Fig 4.11 BSE image of fragmented $\mathrm{MgAl}_{2} \mathrm{O}_{4}$ phase in dross layer from alloy 3004 \#2

Fig 4.12 BSE image of $\mathrm{MgAl}_{2} \mathrm{O}_{4}$ phase and a- $\mathrm{Al}_{2} \mathrm{O}_{3}$ needle-like phase (arrows) in dross layer from alloy $3004 \# 2$

Fig 4.13 Low magnification BSE image of fragmented dross particles in dross layer from alloy 5182

Fig 4.14 BSE image of typical $\mathrm{MgAl}_{2} \mathrm{O}_{4}$ phase in dross layer from alloy 5182

Fig 4.15 Amount of oxide formed vs. time plot for Al-Mg alloys (from Reference 10) with results from present work superimposed

Fig 5.1 Relative concentration of $\mathrm{Al}, \mathrm{Mg}$, and $\mathrm{O}$ in the top few atomic layers of a molten high-Mg aluminum alloy (5182) as a function of added oxygen

Fig 5.2 APS Hutch and sample holder

Fig 5.3 Schematic of experiment

Fig 5.4 X-ray diffraction pattern of a magnesia standard compared to the initial structure that forms on a clean surface of molten high-Mg aluminum alloy (5182)

Fig 6.1 (Top) The ARC Laboratory Scale Reverb in operation during its inaugural heat.

(Bottom) The ARC Laboratory Scale Reverb with the well and plenum sections separated in preparation for clean-up

Fig 6.2 (Top) Dross formation on "prime" aluminum

(Bottom) Dross formation on Al-Mg-Mn Alloy

Both pictures taken immediately after the bath was established, before initial skim

Fig 7.1 Argonne National Laboratory - experimental set up

Fig 7.2 5182 scalper chips - 750C; $24 \mathrm{hrs}$ - not drossed - increase in weight with time - with and without cover

Fig 7.3 5182 scalper chips - 850C; $24 \mathrm{hrs}$ - not drossed - increase in weight with time - with and without cover

Fig 7.4 5052 sheet scrap - 700C; $24 \mathrm{hrs}-$ drossed - increase in weight with time - with and without cover

Fig 7.5 5182 scalper chips - 850C; 24hrs - drossed - increase in weight with time - with and without cover

Fig 7.6 Albany Research Center - experimental set up 


\section{Abbreviations and Acronyms}

\begin{tabular}{|c|c|}
\hline ANL & Argonne National Laboratory \\
\hline ARC & The Albany Research Center \\
\hline ORNL & Oak Ridge National Laboratory \\
\hline UK & The University of Kentucky \\
\hline DOE & Department of Energy \\
\hline IOF & Industry of the Future \\
\hline ITP & Industrial Technologies Program \\
\hline ASM & The American Society of Metals \\
\hline TMS & The Minerals, Metals, and Materials Society \\
\hline IR & Infrared \\
\hline SEM & Scanning Electron Microscopy \\
\hline AES & Auger Electron Spectroscopy \\
\hline BSE & Back Scatter Electron \\
\hline TEM & Transmission Electron Microscopy \\
\hline XPS & X-Ray Photo Electron Spectroscopy \\
\hline EPMA & Electron Probe Micro Analysis \\
\hline APS & Advanced Photon Source - ANL for X-Ray Diffraction \\
\hline EXAFS & Extended X-Ray Absorption Fine Structure \\
\hline SNMS & Secondary Neutral Mass Spectrometry \\
\hline LSRF & Laboratory Scale Reverberatory Furnace - ARC \\
\hline $2-\mathrm{D} \& 3-\mathrm{D}$ & Two and three dimensional \\
\hline TiB2 & Titanium Boride \\
\hline $\mathrm{BN}$ & Boron Nitride \\
\hline AlN & Aluminum Nitride \\
\hline $\mathrm{Al}_{2} \mathrm{O}_{3}$ & Aluminum Oxide \\
\hline $\mathrm{SiC}$ & Silicon Carbide \\
\hline $\mathrm{SiN}$ & Silicon Nitride \\
\hline $\mathrm{CO}$ & Carbon Monoxide \\
\hline $\mathrm{CO}^{2}$ & Carbon Dioxide \\
\hline $\mathrm{H}_{2} \mathrm{O}$ & Water \\
\hline $\mathrm{CH}_{4}$ & Methane \\
\hline $\mathrm{Na}$ & Sodium \\
\hline $\mathrm{Li}$ & Lithium \\
\hline B & Boron \\
\hline $\mathrm{Be}$ & Beryllium \\
\hline $\mathrm{Mg}$ & Magnesium \\
\hline $\mathrm{Mn}$ & Manganese \\
\hline $\mathrm{Fe}$ & Iron \\
\hline $\mathrm{Si}$ & Silicon \\
\hline $\mathrm{Cu}$ & Copper \\
\hline $\mathrm{Zn}$ & Zinc \\
\hline $\mathrm{Cr}$ & Chromium \\
\hline $\mathrm{Ni}$ & Nickel \\
\hline $\mathrm{Ti}$ & Titanium \\
\hline
\end{tabular}




\section{Executive Summary}

\subsection{Research \& Development}

Fabrication of virtually all finished aluminum products requires melting and re-melting of aluminum metal and alloys. During the melting process, aluminum reacts with the furnace atmosphere and oxidizes, forming an aluminum-oxide-rich surface layer called dross resulting in as much as $5 \%$ of the aluminum being oxidized and lost as dross. The amount of oxidative melt loss of aluminum depends on many factors, such as furnace operation (e.g., temperature, atmosphere, stirring, etc.) and the specific surface area, alloy composition, and cleanliness of the feed materials. In the U.S., an energy loss of roughly 70 trillion Btu/yr. results from oxidative melt loss of over 960 million pounds of $\mathrm{Al}$ and its alloys.

The project addressed the fundamental mechanisms of dross formation and identifies techniques and process changes that would significantly reduce the oxidation of aluminum during melting. A reasonably achievable target is a $50 \%$ reduction in oxidative melt loss leading to a reduction in dross losses from about $4 \%$ to $2 \%$. Full scale implementation of the results of the proposed research would lead to energy savings in excess of 58 trillion Btu by the year 2020. If successful, the technology developed in this project will lower the cost of aluminum products, reduce energy consumption in aluminum fabrication, reduce industrial emissions, and significantly increase the recycling capability of the aluminum industry.

The project focused on the fundamental understanding of the behavior of dross formation, understanding its kinetics and the factors that effect the formation of dross based on process variables during the melting and re-melting of aluminum and its alloys. To understand this phenomenon it was decided to first collect and evaluate samples from the various participating industrial partner facilities consisting of starting materials, cast alloys, and dross - and from four alloy classes. The alloy classes chosen for this work consisting of alloy 1350, 3004, 3105, and 7075 that span a significant range in material uses, properties and alloying elements.

The collected samples were analyzed in several ways and form the basis for dross growth rate limitation studies. Carefully controlled experiments were carried out using the facilities at the Argonne National Laboratory. Alloy samples were melted and the dross growth studied in situ by XPS, EXAFS and SNMS as a function of furnace atmosphere (with initial emphasis on $\mathrm{CO}_{2} / \mathrm{CO}$ ratio and $\mathrm{H}_{2} \mathrm{O}$ content), and minor impurities with the intent of developing conditions for limiting dross growth and extending the time for dross nucleation and formation. In concert with these studies, industrial samples of dross were analyzed.

Careful comparison of the industrially-generated dross with the dross formed on laboratory-investigated specimens were made to understand the factors necessary to extrapolate laboratory-based measurement to industrial melting environments and to understand the potential for scaling bench technology to industrial scale systems. Bench scale tests were conducted using the facilities at the Albany Research Center and the University of Kentucky.

The tests conducted were used to evaluate three concepts proposed as causing dross formation during melting.

1. Careful control of furnace atmosphere can be used to slow the growth of dross oxide films by producing oxide films with significantly reduced oxygen diffusion rates. Since it is known that aluminum oxide formation progresses by transport of $\mathrm{Al}$ atoms through the growing oxide film to the film surface where it can be attacked by a variety of oxidizing agents in the furnace atmosphere, well-ordered defect free oxide films can form a significant barrier to oxidation as it does on the base metal at room temperature. 
2. Minor elements in the melt, both alloying and impurity, can also dramatically affect the oxide layer composition and growth kinetics.

3. Oxide growth can be limited by decreasing the melt surface exposure to furnace atmosphere.

The main achievements that resulted during the course of the project include

1. Understanding the kinetics of dross formation and the effect of different alloying elements on dross formation. It was determined that the dross evolves in similar ways regardless of the aluminum alloy being melted and the results showed that amorphous aluminum nitride forms first, followed by amorphous magnesium oxide and crystalline magnesium oxide in all alloys that contain magnesium. Evaluation of the molten aluminum alloy surface during melting and holding indicated that magnesium oxide is the first crystalline phase to form during oxidation of a clean aluminum alloy surface. Based on dross evaluation and melt tests it became clear that the major contributing factor to aluminum alloy dross was in the alloys with $\mathrm{Mg}$ content.

2. $\mathrm{Mg}$ was identified as the primary factor that accelerates dross formation specifically in the transition from two phases to three phase growth. Limiting magnesium oxidation on the surface of molten aluminum therefore becomes the key to minimizing melt loss, and technology was developed to prevent magnesium oxidation on the aluminum surface. This resulted in a lot of the work being focused on the control of $\mathrm{Mg}$ oxidation.

3. Identified two potential molten metal covering agents that would inhibit dross formation during melting and holding consisting of boric acid and boron nitride tiles. The latter was discounted by industry as it resulted in Boron pick up by the melt beyond that allowed by specifications during plant trials.

4. Developed an established method for collection of samples at industrial sites in order to be able to compare samples from different sites and different alloys.

5. Developed a sophisticated method for evaluating dross formation at the Argonne National Laboratory using XPS.

6. A patent was filed on one covering agent Boron Nitride tiles by Argonne National Laboratory and is available for implementation by industry based on their interest.

7. The understanding of the kinetics of dross formation by the industry partners helped them understand how temperature, alloy chemistry and furnace atmosphere (burner controls- e.g. excess air) effected dross formation. This enables them to introduce in their plant process changes that reduced unnecessary holding at high temperatures, control burner configurations, reduce door openings to avoid ingress of air and optimize charge mixes to ensure rapid melting and avoid excess oxidation. 


\subsection{Technology Transfer}

The knowledge and understanding generated during the course of the project has been disseminated to all industry partners including the development of a laboratory sized facility to carry out melt trials at the Albany Research Center as well as development of a sophisticated method for evaluating dross formation at the Argonne National Laboratory using XPS. This is available for future use by industry participants.

\subsection{Commercialization}

Project participants have used several mechanisms to inform industries of the research results and advance commercialization including launching Aluminum Answers, a Secat website, partly for disseminating the latest research results into the aluminum industry, and making presentations at national meetings organized by the Minerals, Metals, and Materials Society (TMS), and the American Society of Metals (ASM), and implementing the results and findings at industrial locations. The results generated at these sites are considered proprietary.

A patent was filed on one covering agent Boron Nitride tiles by Argonne National Laboratory and is available for implementation by industry based on their interest.

\subsection{Recommendations}

This research project has successfully demonstrated that an increased understanding of the kinetics of dross formation and its behavior can lead to better controls within the plant to reduce dross and improved efficiencies. It would be good to carry out additional research on other alloys not covered in this project and perhaps develop some computational tools that would enable prediction of dross formation based on alloy chemistry, temperature of operation and protective covers. 


\section{Introduction}

The oxidation resistance of $\mathrm{Al}$ at room temperature results from the coherent growth of a thin, defect-free oxide film that is a barrier to further oxygen transport. At elevated temperatures, the large differential thermal expansions of the oxide and metal lead to film growth with defects and rapid oxidation of both the solid and the melt. Various investigators have examined the oxidation of aluminum from a fundamental point of view, but typically, these studies have been performed over a limited temperature range and/or under limited atmospheric conditions.(Beranek and Sebkova, 1980; Buechen, 1988; Chatillon et al., 1997; Chol et al., 1989; Cochran et al., 1976; Cochran et al., 1977; Crepeau et al., 1992; Drouzy and Fontaine, 1970; Drouzy and Mascre, 1969; Drouzy and Richard, 1974; Field and Butler, 1984; Gerlach and Hennig, 1982; Haginoya and Fukusako, 1979; Haginoya and Fukusako, 1981; Haginoya and Sato, 1985; Impey et al., 1993; Santos Correa and Torem, 1996; Sata, 1994; Shyr, 1997; Stucki et al., 1987; Wightman and Fray, 1983) These studies have shown that the dross composition and growth rate is dramatically affected both by the furnace atmosphere $(\mathrm{CO} 2 / \mathrm{CO}$ ratio and $\mathrm{H} 2 \mathrm{O}$ content $)$ and by minor alloying constituents in the melt ( $\mathrm{Mg}, \mathrm{Li}, \mathrm{Si}$, etc.). Moreover, because most of these oxides are significantly denser than molten $\mathrm{Al}$, surface tension and oxide island growth must also play a significant role in the growth rate of all three mechanisms of oxidative loss. Dross growth seems to be at least biphasic with a rapid increase in film growth accompanying a change in oxide film structure from "amorphous" to "crystalline". Alternatively this change in growth rate has been described as nucleation of three-dimensional growth following a slower two-dimensional growth phase. The incubation time for this change also appears to depend not only on the above factors, but also on the initial state of the input material (e.g., cleanliness, specific surface area, and perhaps loading configuration) (Impey et al., 1993; Santos Correa and Torem, 1996). Extension of this incubation time beyond the time typically used in an industrial melt and pour cycle would at once dramatically reduce oxidation losses, extend recycling times, reduce industrial wastes, and decrease the energy requirements of the Semi-Fabricated Sector of the aluminum industry.

Recent years have seen the development of powerful new tools for the study of growing oxide films. Concomitant with new research results has come a fundamental understanding of the variables that control oxidation rates. The liquid aluminum surface is in many ways an ideal system on which to apply these new techniques. Al has a low vapor pressure over the melt and, as a liquid, has a simple atomic ordering. On liquid metal surfaces, surface segregation of minor melt components can play a significant role in oxidation since the liquid allows facile diffusion of these impurities to the liquid metal - solid oxide interface. Although the thermodynamics of this segregation have been well understood since Gibbs' time, the kinetics model, however, is more difficult and is currently an active area of research. The thermodynamic driving force for segregation arises from the different bond enthalpies available to impurities and bulk atoms in the melt, at the interface, and in the oxide. Because minor elements (whether alloying or impurity) can be strongly concentrated into the interfacial dross-growing region, and because their presence in the oxide layer can strongly influence the ability of the oxide to act as barrier layer to oxygen transport, it is absolutely necessary to study systems under conditions of industrial interest.

We propose to combine the analytical tools available at two National Laboratories (ANL and ORNL) with the expertise, materials and capabilities of Secat member companies. Because minor alloying and impurity elements have a significant and often synergistic role in dross growth rates - a role that is strongly affected by the furnace-melting environment, it is absolutely necessary that laboratory studies accurately reflect the starting materials, furnace conditions, and furnace atmospheres present in industrial melting practices. Secat member companies will begin this project with the collection and validation of a significant number of aluminum samples. These samples will be of three types - starting materials, cast alloys, and dross - and be from four alloy classes. The alloy classes chosen for this work: 1350, 3004, 3105, and 7075 span a significant range in material uses, properties and alloying elements. In 
collecting these alloys, it will be necessary for Secat member companies to carefully examine the issue of sampling in order to derive a representative set of samples for each alloy class. It is expected that at least 10 different samples of each type from each alloy class will be collected. Samples will be taken from melts of different starting materials, at different times of the year (to determine humidity effects), and from different furnaces. Each of the 10 samples will be tagged with as much pertinent information as possible including material properties of the finished castings.

Collected samples will be analyzed in several ways and will form the basis for dross growth rate limitation studies based on the three concepts below. Four each sample type and alloy class, a fraction of the ten collected samples will be homogenized to produce a representative "average" sample for study. Each of the ten individual samples will be studied to ascertain diversity. At the National Laboratories, alloy samples will be melted and the dross growth studied in situ by XPS, EXAFS and SNMS as a function of furnace atmosphere (with initial emphasis on $\mathrm{CO} 2 / \mathrm{CO}$ ratio and $\mathrm{H} 2 \mathrm{O}$ content), and minor impurities. The intent will be to develop conditions for limiting dross growth and extending the time for sample nucleation. In concert with these studies, industrial samples of dross will be analyzed. Careful comparison of the industrially-generated dross with the dross formed on laboratory-investigated specimens will be made to understand the factors necessary to extrapolate laboratory-based measurement to industrial melting environments and to understand the potential for scaling bench technology to industrial scale systems.

As conditions and melting practices are suggested to limit dross growth, full-scale melting tests will be conducted at member companies to validate the concepts. Samples and analysis will be taken of these tests to provide a more complete picture of the scale-up parameters between laboratory and industrial scale tests.

The project addressed the fundamental mechanisms of dross formation identify techniques and process changes that that would significantly reduce the oxidation of aluminum during melting. A reasonably achievable target is a 50\% reduction in oxidative melt loss leading to a reduction in dross losses from about $4 \%$ to $2 \%$. Full scale implementation of the results of the proposed research would lead to energy savings in excess of 58 trillion Btu by the year 2020. If successful, the technology developed in this project will lower the cost of aluminum products, reduce energy consumption in aluminum fabrication, reduce industrial emissions, and significantly increase the recycling capability of the aluminum industry. 


\section{Background}

\subsection{Project Goal and Scope}

The project goal is to reduce oxidative melt loss for the Aluminum industry from a current $4 \%$ loss to $2 \%$ in the future. The partnership will accomplish this goal by careful control of melt exposure to the furnace atmosphere, through the use of minor elements that dramatically affect the kinetics of oxide growth, and by decreasing the melt surface area through various techniques.

Molten aluminum oxidation proceeds with the transport of oxidative species through the dross layer to the metal interface where the reaction takes place. At room temperature, the growing oxide layer forms a barrier that limits further transport and subsequent growth. We propose that despite the large thermal expansion differences between the oxide and the metal, melting practices can be developed that substantially reduce metal oxidation without significant modification of current melting furnaces. This will be accomplished by the appropriate combination of three methods. First, the composition, structure and growth rate of dross is strongly dependent on the furnace atmosphere during melting. The effect of variables such as $\mathrm{CO} / \mathrm{CO} 2$ ratio, $\mathrm{H} 2 \mathrm{O}$ content and residual fuel content $(\mathrm{CH} 4)$ has never been systematically investigated under conditions applicable to industrial melting environments. Second, while it is well-known that alloying elements and impurities can be strongly segregated into the growing dross, we suggest that the segregation of these minor elements can be used to grow complex oxides with lattice parameters well matched to the molten metal surface. The barrier oxide thus formed will perform the same function as aluminum oxide on aluminum metal at room temperature. Finally, we propose that the melt/furnace atmosphere exposure can be limited by the use of floating oxide balls that can be pushed aside for pouring operations.

The scope of the proposal includes preparing and collecting aluminum and dross samples, characterizing their variability, and investigating their oxidation kinetics and evaluating concepts that would decrease their oxidation rate. Melts to be investigated will include four basic alloy groups - 1350, 3004, 3105, and 7075. The dross grown will be compared in both composition and morphology to industrial generated dross taken from the same sample melts. Promising melt practices will be modeled and investigated on an industrial scale, as they become evident. Effects to be investigated include: the effect of furnace atmosphere composition ( $\mathrm{CO} 2 / \mathrm{CO}$ ratio and $\mathrm{H} 2 \mathrm{O}$ content); the effect of limiting melt surface exposure to the atmosphere; the effect of minor alloying elements; the effect of charge loading configuration; the effect of scrap cleanliness (e.g., oil coating, water coating, pre-existing oxide (weathered, presence of salt,)); and the effect of stirring and subsequent virgin Al surface exposure and oxidation.

Studies will be undertaken to determine the effect of decreasing the melt exposure to furnace atmosphere with the intent of delaying the 2-D to 3-D growth phase transition beyond typical melt cycle times. We suggest that small (perhaps hollow) golf-ball-sized spheres of inert, low density materials such as zeolite or aluminolithium oxides could be floated on the melt surface dramatically reducing contact of the growing dross film with the furnace atmosphere. In this way the low-growth-rate incubation period of dross growth might be extended beyond the melt cycling time without significantly affecting current loading and melting operations. The spheres may be effective for multiple heats before they would need to be replaced. Key to the successful implementation of this concept is identifying oxide materials with low emissivity and high radiative absorption in order to balance loss of convective heating.

\subsection{Statement of Objectives}

The objective of this project is to develop technology that will reduce oxidative melt loss of aluminum and its alloys from $4 \%$ of the aluminum melted to $2 \%$. The main goals of the project include 
1. Develop an understanding of the effects of alloy class, furnace atmosphere and tramp elements on dross growth as a first step in order to understand and extend the time before oxide growth undergoes a transition from two dimensional growth to three dimensional growth.

2. This understanding will be used to develop industrial melting practices that reduce oxidative melt loss.

3. In the course of these studies an increased fundamental understanding of the oxidation of molten aluminum will be developed that can be applied to a cross-section of the aluminum industry.

\subsection{Work breakdown structure}

\section{Task 1. Sample Protocols}

Establish sampling procedures, tagging methods, archival storage, and web based access to sample information. Accurate sampling methods of each of starting materials, cast alloy and dross from individual melts of each of the four alloy types are necessary to allow results generated to accurately model industrial melting conditions. The samples need to be labeled with information concerning their generation including company, date, atmospheric conditions, etc. These samples will be drawn from research throughout this project and need to be archived and stored.

\section{Task 2. Standard Alloys}

Industrial Alloy Standard materials need to be prepared for testing. These standards need to be properly sampled to account for starting material variability in cleanliness and tramp elements as well as minor element variations. Each alloy standard will be developed at a member company by taking 50 pound ingots from 10 separate melts of each alloy standard. The ingots will be collected over varying times during the calendar year tagged with as much supporting information as possible including starting alloy form, shape, melting temperature, furnace atmosphere, and supplier. Each of the 10 samples for each of the four alloys will consist of three parts - starting materials, aluminum ingot and dross. The starting material sample will be a representative part of the starting materials used in each melt. The aluminum ingot will be a part of the casting. The dross will be sampled by scooping at tapping time just prior to skimming, in the middle of the melt cycle, and before the charge is completely melted.

\section{Task 3. Alloy Characterization}

Characterization of the collected cast alloy samples will be analyzed for both average composition and variability among samples. Measurements of each of the alloy samples (4 alloys) will be made for minor and tramp composition on an average composition and then in following years on individual samples to measure both the average and the variation in composition of the aluminum ingot and dross. The purpose of this research is to ascertain the variability in dross composition as a function of alloy type and of tramp element composition. Also we will determine the variation of minor and tramp elements in the alloy material itself.

\section{Task 4. Dross Sample Analysis}

Dross specimens from actual industrial melting processes will be analyzed to (i) determine effects of variations in melt chemistry on dross formation, composition, and morphology; (ii) establish general tendencies of elemental partitioning to dross; and (iii) identify mechanism(s) for breakdown of protective alumina film on melt. The presence of tramp impurities in the dross at levels exceeding their bulk concentrations will signal their importance in the dross formation process.

\section{Task 5. Oxidation Kinetics}

Average aluminum ingots of each alloy type will be used in test studies to monitor the kinetics of oxide formation at the APS. These studies will focus on the kinetic effects of furnace atmosphere composition 
on oxide film growth rate and composition. These studies will be done as a function of alloy type and will focus on the nucleation time for the change from 2-D to 3-D growth with the hope of extending this time. APS EXAFS and XPS lines will be used in this effort.

\section{Task 6. Dross Comparisons}

Compare synthetic dross compositions prepared in Task 5 with industrial samples studied in Task 6. Composition and microstructure differences will be examined in order to understand the differences between industrial scale and laboratory scale experiments with the objective of extrapolating laboratory results to industrial practice. This work, in conjunction with ANL, will also examine mechanism(s) for breakdown of protective alumina film by characterizing oxides at various stages of development.

\section{Task 7. Growth Mode}

Kinetic studies conducted in Task 4 will be used to time the transition between 2-D to 3-D dross growth with the objective of stopping oxidation during the transition. Compositional imaging with high lateral resolution will be used to study the nucleation sites in order to better understand the mechanics of this transition.

\section{Task 8. Alternative Dopants}

Studies of Task 4 will be broadened to investigate variables for specific alloys that have a large effect on growth rate. In particular we will study the changes that occur by doping alloys with selected elements such as $\mathrm{Na}, \mathrm{Li}, \mathrm{Mg}, \mathrm{B}$ and $\mathrm{Be}$.

\section{Task 9. Melt Exposure}

Studies will be undertaken to determine the effect of decreasing the melt exposure to furnace atmosphere with the intent of delaying the 2-D to 3-D growth phase transition beyond typical melt cycle times. We suggest that small (perhaps hollow) golf-ball-sized spheres of inert, low density materials such as zeolite or aluminolithium oxides could be floated on the melt surface dramatically reducing contact of the growing dross film with the furnace atmosphere. In this way the low-growth-rate incubation period of dross growth might be extended beyond the melt cycling time without significantly affecting current loading and melting operations. The spheres may be effective for multiple heats before they would need to be replaced. Key to the successful implementation of this concept is identifying oxide materials with low emissivity and high radiative absorption in order to balance loss of convective heating.

\section{Task 10. Agitation}

Alloy form and stirring can only be studied effectively in melts larger than laboratory scale. First pilotscale melts will be made in an atmosphere-controlled electric resistance furnace. Gas-fired pilot-scale reverberatory and/or electric induction furnaces may be used to simulate industrial practice as the project matures. These systems will be tested on a few samples to ascertain whether alloy form and stirring are important factors are important factors in dross growth. The most important variables identified in Task 3 will be used to identify charge compositions to be studied.

\section{Task 11. Scale-up}

Large Melt batches will be used to validate dross limitation steps that have been suggested in Tasks1-7 and to again demonstrate that laboratory-scale studies accurately model conditions in industrial furnaces.

\section{Task 12. Modeling}

Modeling of thermodynamics, heat transfer, and diffusion, during melting and oxidation of aluminum in ANL experiments and industrial furnaces

This task was not carried out based on feedback from industry participants who felt that without getting a good understanding of other tasks this would not be meaningful. 


\section{Microstructural Evaluation of Industrial Dross (Task 1, 2, 3, 4 and 6)}

\subsection{Introduction}

Loss of Al during commercial re-melting is a problem for the $\mathrm{Al}$ industry due to oxidation of the molten Al.[1-4] Aluminum dross, the oxidation product containing metal and numerous metal oxide phases, can form in significant amounts during the melting process. In fact, the average Al loss due to oxidation is $\sim 4 \%$, or $\sim 480,000$ tons per year, for the United States aluminum industry.[5] Molten aluminum alloys with no $\mathrm{Mg}$ additions will oxidize relatively slowly, however, the addition of even small amounts of $\mathrm{Mg}$ to the melt will cause significantly greater oxidation rates due to the accelerated rate of formation of magnesium aluminate spinel.[2,4,6-10] The purpose of this project was to understand the mechanisms of dross formation in industrial furnaces and, with this knowledge, to investigate possible ways by which to inhibit the rate of formation of dross on various classes of commercial Al alloys.

The first part of the project was to characterize industrial drosses. There have been several previous studies on the evaluation of $\mathrm{Al}$ dross collected from industrial melt furnaces, where the dross has been characterized in terms particle size, phase content, and metal content.[3,11,12] However, relatively little work has been done to fully characterize the microstructure/phase evolution during industrial melting and to relate the amounts and types of phases formed to the particular industrial melt practice utilized, particularly since dross can vary so greatly and is dependent on many different compositional and processing factors.[1,2,4,6,7,9-11] Work of this type has usually been done on a proprietary basis by an individual company for a particular $\mathrm{Al}$ alloy and melt practice and, thus, results are generally not reported in the open literature. Most of the detailed characterization that has been reported has been conducted on relatively pure $\mathrm{Al}$ alloys melted in the laboratory [8-10] which, while providing valuable information with regard to dross growth mechanisms under controlled conditions, may not be representative of the more varied microstructural development associated with large-scale industrial furnaces.

The issue of variations in industrial dross formation for both $\mathrm{Mg}$ - and non-Mg-containing $\mathrm{Al}$ alloys was addressed so as to develop an improved understanding of the important factors that contribute to the formation of different dross microstructures and morphologies and to identify any common mechanisms and features. This was accomplished by conducting extensive microstructural characterization of bulk Al dross specimens from $\mathrm{Mg}$ - and non-Mg Al alloys from different industrial Al-melt furnaces. Such information formed one of the bases for evaluating the relevance of laboratory investigations and possible process modifications to reduce $\mathrm{Al}$ loss from dross formation during melting.

\subsection{Experimental Procedure}

The dross of aluminum alloys that were investigated are listed in Table 4.1 along with the alloy compositions as determined by chemical analysis of metal buttons taken from the melt at the same time as the dross samples. The metal charge for alloy 1350 (no $\mathrm{Mg}$ ) was all prime and the dross sample was collected at a metal melt temperature of $767^{\circ} \mathrm{C}$. Two different industrial furnaces were used to collect dross from the surface of molten alloy 3004. The furnace used for melting the first batch of alloy 3004 (3004 \#1), which was actually the molten precursor for blending the second melt of alloy 3004, was a reverberatory melter and was charged in a side bay with a charge mix of $80 \%$ unpainted beverage cans and $20 \%$ painted siding. The dross from this furnace was collected from the furnace at a metal melt temperature of $\sim 780^{\circ} \mathrm{C}$. The charge mix for the second batch of alloy 3004 (3004 \#2) was not identified; however, transferred molten alloy 3004 \#1 was part of the charge. The dross specimen was collected at metal melt temperature of $690^{\circ} \mathrm{C}$. Alloy 3004 was the low $\mathrm{Mg}$ alloy used in this study. For an $\mathrm{Al}$ alloy with a high $\mathrm{Mg}$ content, alloy 5182 was selected for comparison with the other two alloys. The furnace charge mix used for alloy 5182 was not known. The alloy 5182 dross sample was collected at $695^{\circ} \mathrm{C}$. 
Alloy Composition (wt \%)

$\begin{array}{lccccccccc} & \mathrm{Mg} & \mathrm{Mn} & \mathrm{Fe} & \mathrm{Si} & \mathrm{Cu} & \mathrm{Zn} & \mathrm{Cr} & \mathrm{Ni} & \mathrm{Ti} \\ \text { Alloy } 1350 \text { collected at } 7 \mathbf{6 7}^{\circ} \mathbf{C} & 0.00 & 0.00 & 0.11 & 0.04 & -- & 0.01 & -- & -- & -- \\ \text { Alloy } 3004 \# 1 \text { collected at } 777^{\circ} \mathbf{C} & 1.01 & 0.81 & 0.52 & 0.22 & 0.17 & 0.07 & 0.27 & 0.11 & 0.02 \\ \text { Alloy } 3004 ~ \# 2 \text { collected at } 690^{\circ} \mathbf{C} & 0.86 & 1.02 & 0.47 & 0.19 & 0.13 & -- & -- & -- & -- \\ \text { Alloy } 5182 \text { collected at } 695^{\circ} \mathbf{C} & 4.13 & 0.34 & 0.20 & 0.09 & 0.04 & -- & -- & -- & --\end{array}$

Table 4.1: Compositions of Al alloys from metal button analysis

Metal samples were collected from the molten metal bath below the dross layer at the same time as the dross specimens were taken.

The Al dross specimens collected from the different industrial furnaces were all taken using a similar sampling protocol. They were collected using a special red-clay crucible (nominally $10-15 \mathrm{~cm}$ in diameter at the surface and $10 \mathrm{~cm}$ deep) that was held in place at the end of a long steel rod. The specimens were collected manually near the front door of the furnaces. The crucible was dipped sideways below the surface into the molten Al, rotated, and then scooped upward in order to collect both molten metal and the surface dross layer. The dross specimens were taken from each furnace before any skimming or stirring of the melt and after holding the molten alloy at the melt temperature for $\geq 0.5 \mathrm{~h}$. The dross samples were allowed to cool inside the crucibles. Metal button samples were collected at the same time and from the same area of the furnace as the dross samples in order to determine the chemistry of the molten alloy.

After cooling completely, the bulk Al dross specimens were removed from the crucibles and each was cut in half (top to bottom) using a band saw. A typical dross sample before cutting is shown in Fig 4.1. One half of the solid dross was then mounted in epoxy and polished. In this way, the entire dross layer was viewed in cross-section and particular areas for detailed microstructural characterization were carefully selected. A typical cross-sectioned bulk dross specimen is shown in Fig 4.2.

In general, areas of the dross layer selected for further investigation included regions at the atmosphere/melt interface, isolated sub-surface particles, and regions near metal/oxide boundaries. The particular areas selected for evaluation were typically removed by cutting directly from the mounted cross-section (shown by the boxes in Fig 4.2.) Extensive electron probe microanalysis (EPMA) was conducted on the individual cross-sectional areas to assess the morphological and compositional differences between the $\mathrm{Al}$ dross specimens collected from the surface of the different molten alloys and $\mathrm{X}$-ray diffraction provided information regarding crystalline phase content. Backscatter electron (BSE) imaging in the EPMA was used to enhance compositional differences within the dross samples. Transmission electron microscopy (TEM) was also conducted on several dross specimens. 


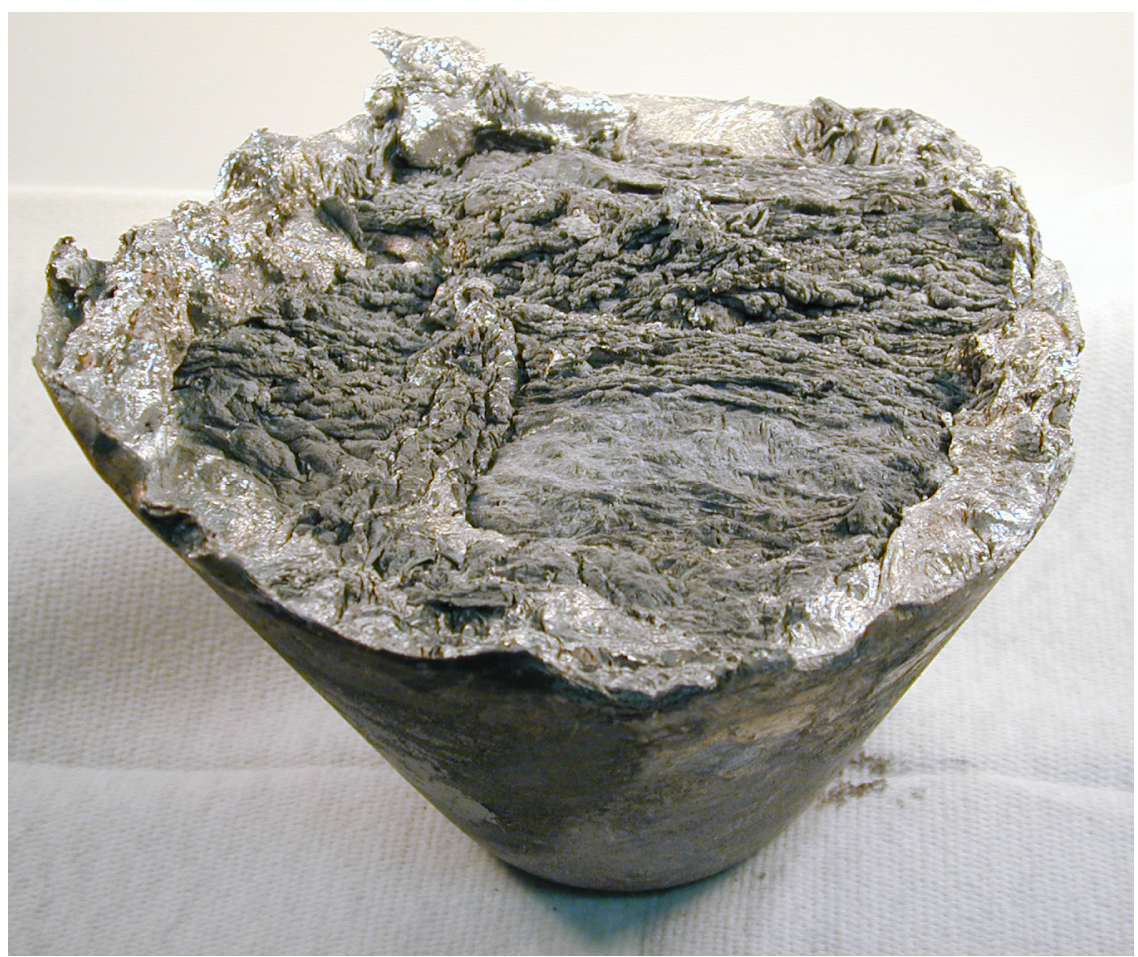

Fig 4.1: Bulk dross sample ( $\sim 10-15 \mathrm{~cm}$ diameter at surface and $10 \mathrm{~cm}$ deep) after cooling and removing from crucible.

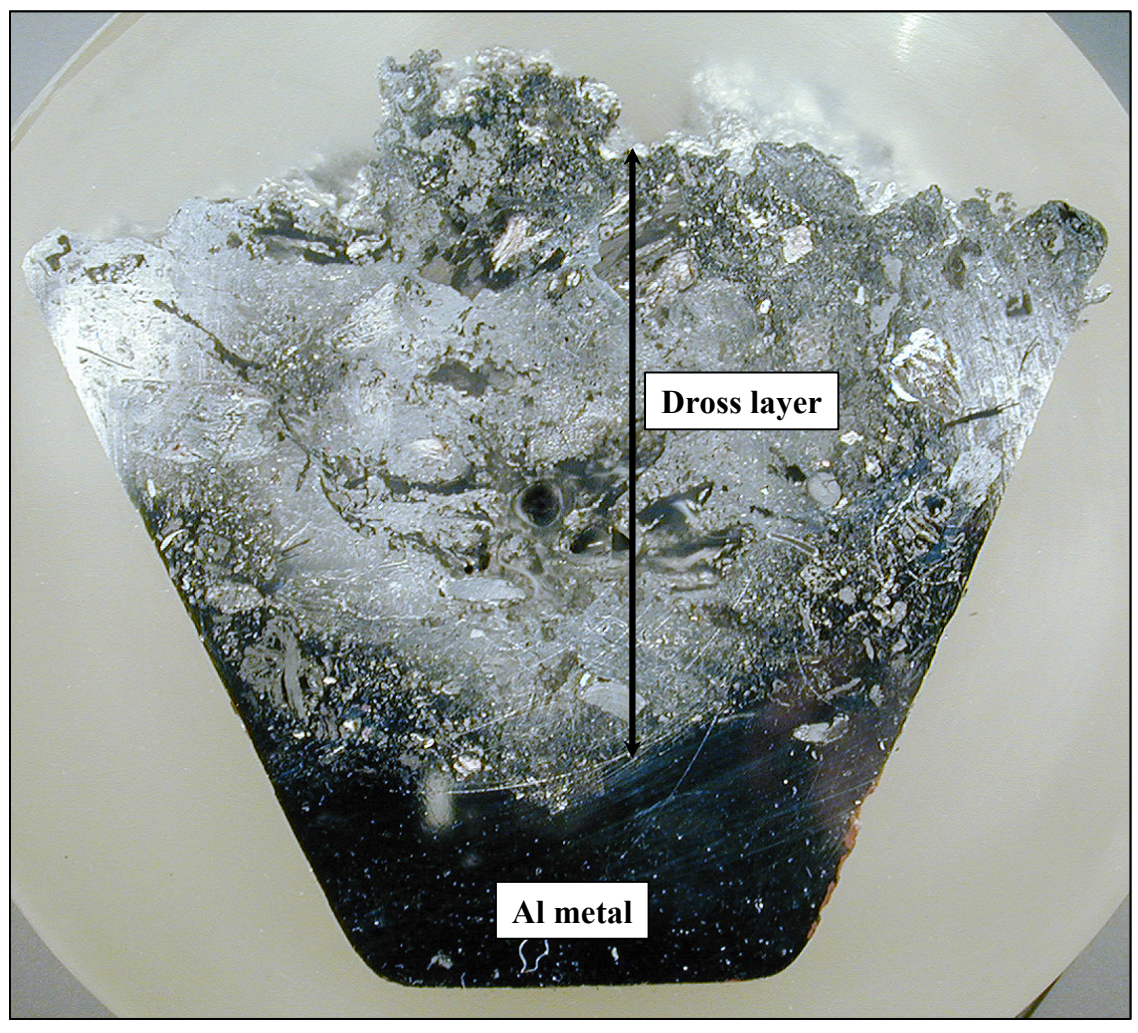

Fig 4.2: Cross-section of bulk dross sample showing the dross layer at the surface. 


\subsection{Results and Discussion}

4.3.1 Alloy 1350 (no Mg) - The thickness of the dross layer on the molten 1350 alloy was $\sim 3 \mathrm{~cm}$. The oxide-rich regions within the dross layer, from the surface to the metal/oxide interface, typically had a layered structure, as shown in Fig 4.3. The extensive network of layered oxides trapped Al metal within individual dross particles. This layered morphology is also shown in Fig 4.4, which is a higher magnification image of the boxed area in Fig 4.3. There were three distinct phases, or layers, identified consistently throughout the dross; a primary microcrystalline $\mathrm{Al}_{2} \mathrm{O}_{3}$ (labeled $\mathrm{A}$ ), a cracked, large grained $\mathrm{Al}_{2} \mathrm{O}_{3}$ phase (labeled a), and an acicular phase between the two $\mathrm{Al}_{2} \mathrm{O}_{3}$ layers (labeled $\mathrm{B}$ ). $\mathrm{The}^{\mathrm{Al}} \mathrm{I}_{2} \mathrm{O}_{3}$ phase compositions were initially ascertained by EPMA compositional analysis. The elemental maps shown in Fig 4.5 for Al, O, N, and Ti, were collected from the same layered region shown in Fig 4.4. The high $\mathrm{N}$ signal (in the $\mathrm{N}$ map) and low $\mathrm{O}$-signal (in the $\mathrm{O}$ map) regions corresponded directly with the acicular phase (see Figure 4) and indicated that it was AlN. X-ray diffraction results were used to identify two major crystalline phases within the dross, $\alpha-\mathrm{Al}_{2} \mathrm{O}_{3}$ and AlN. The Ti-rich inclusions (see brightly imaging areas in Fig 4.4 and Ti map in Fig 4.5) were due to the addition of $\mathrm{TiB}_{2}$ as an $\mathrm{Al}$ grain refiner. The cracked, large grained $\mathrm{Al}_{2} \mathrm{O}_{3}$ phase (labeled "a" in Fig 4.4) was amorphous, as determined by TEM electron diffraction. A BSE image from another part of the alloy 1350 dross sample is shown in Fig 4.6. A similar layered product morphology and compositional distribution to what was described for Fig 4.3 to 4.5 was found here and elsewhere in the sample.

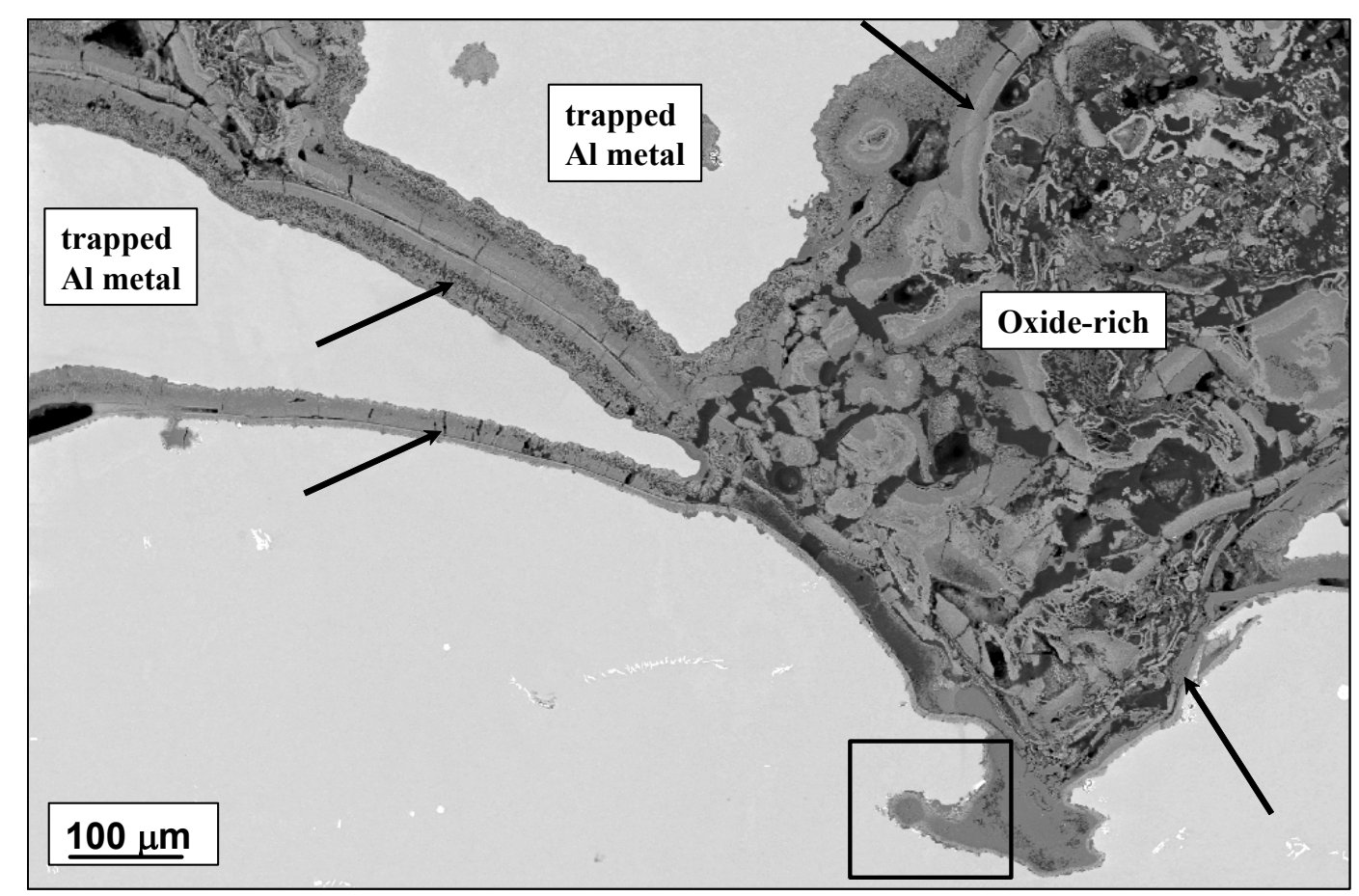

Fig 4.3: BSE image showing layered structure (denoted by arrow) in an oxide rich region in dross collected from molten 1350 


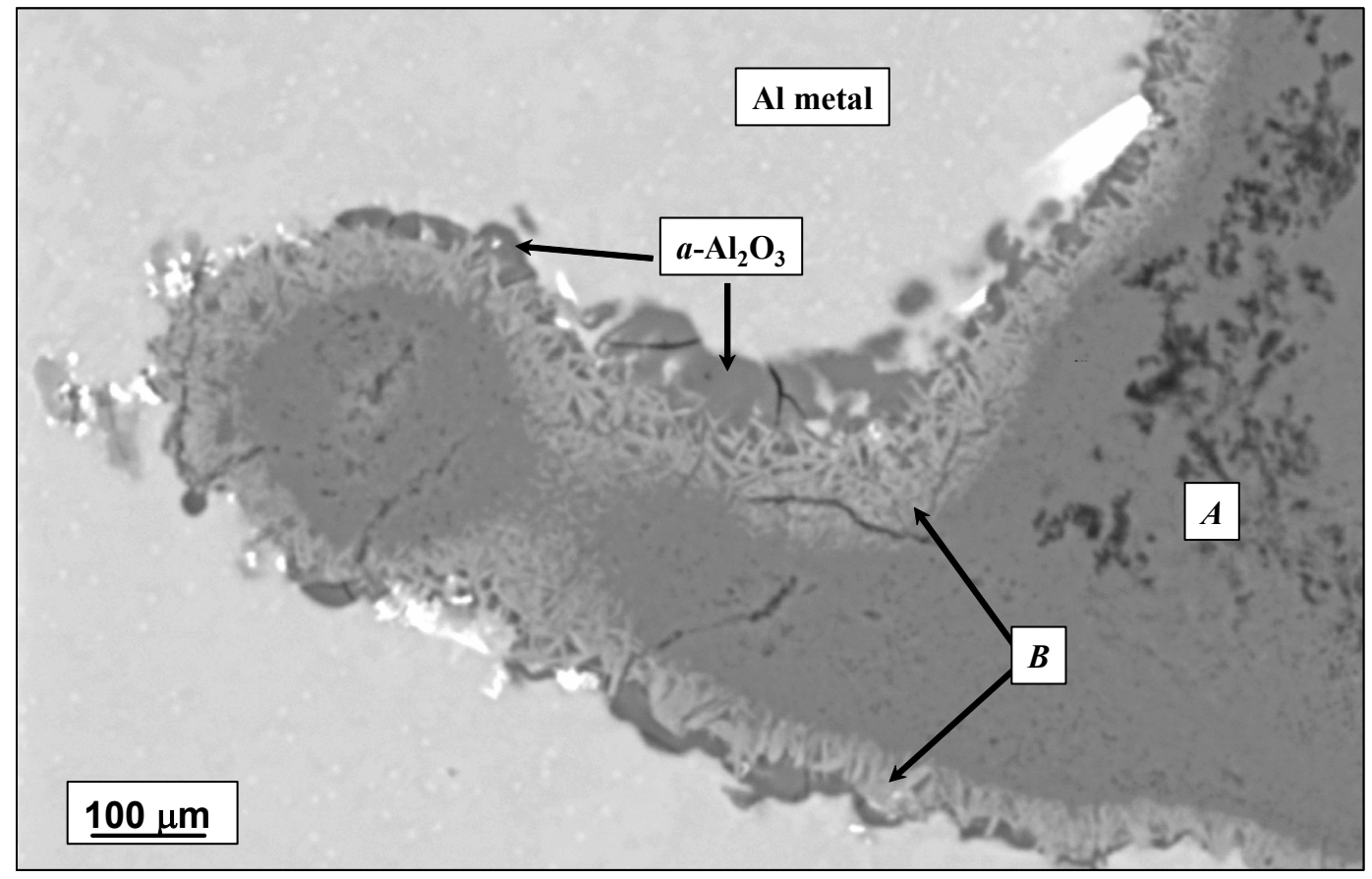

Fig 4.4: Higher magnification BSE image of area within box in Figure 3 showing 3-layer structure in dross collected from molten 1350.
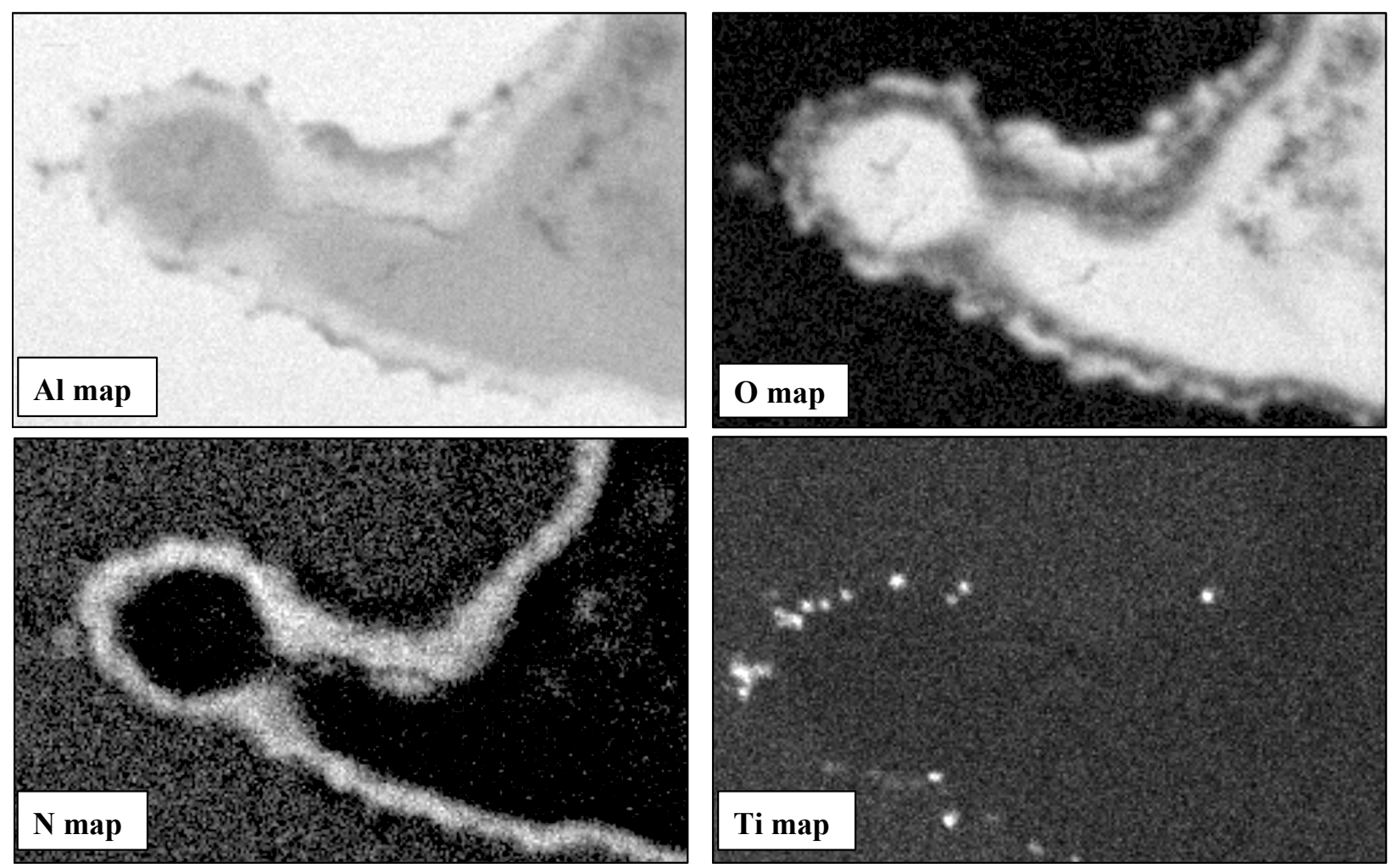

Fig 4.5: Elemental maps for Al, O, N, and Ti from same region shown in Fig 4 


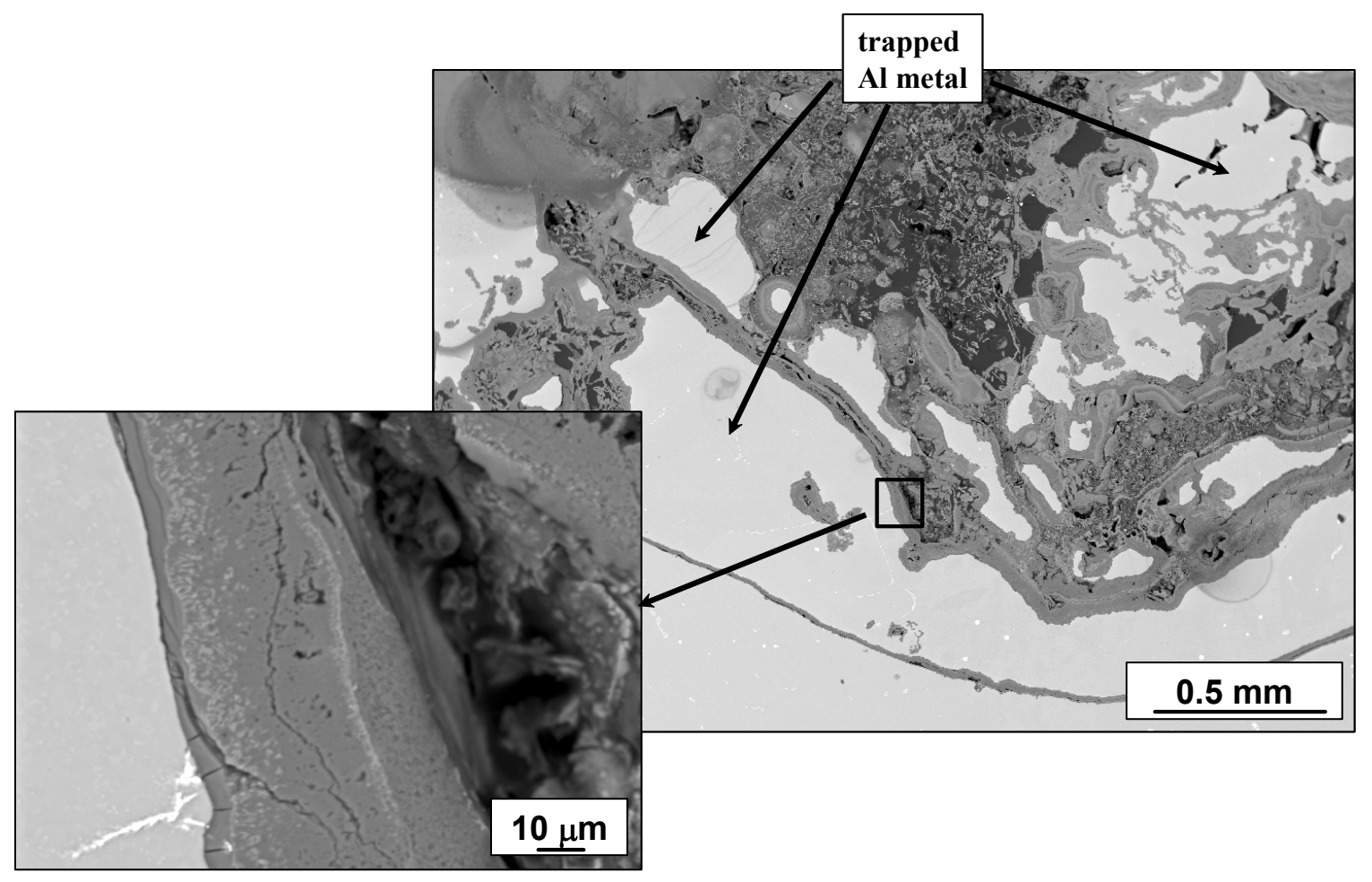

Fig 4.6: BSE image showing layered structure in oxide-rich region-dross collected - molten alloy 1350.

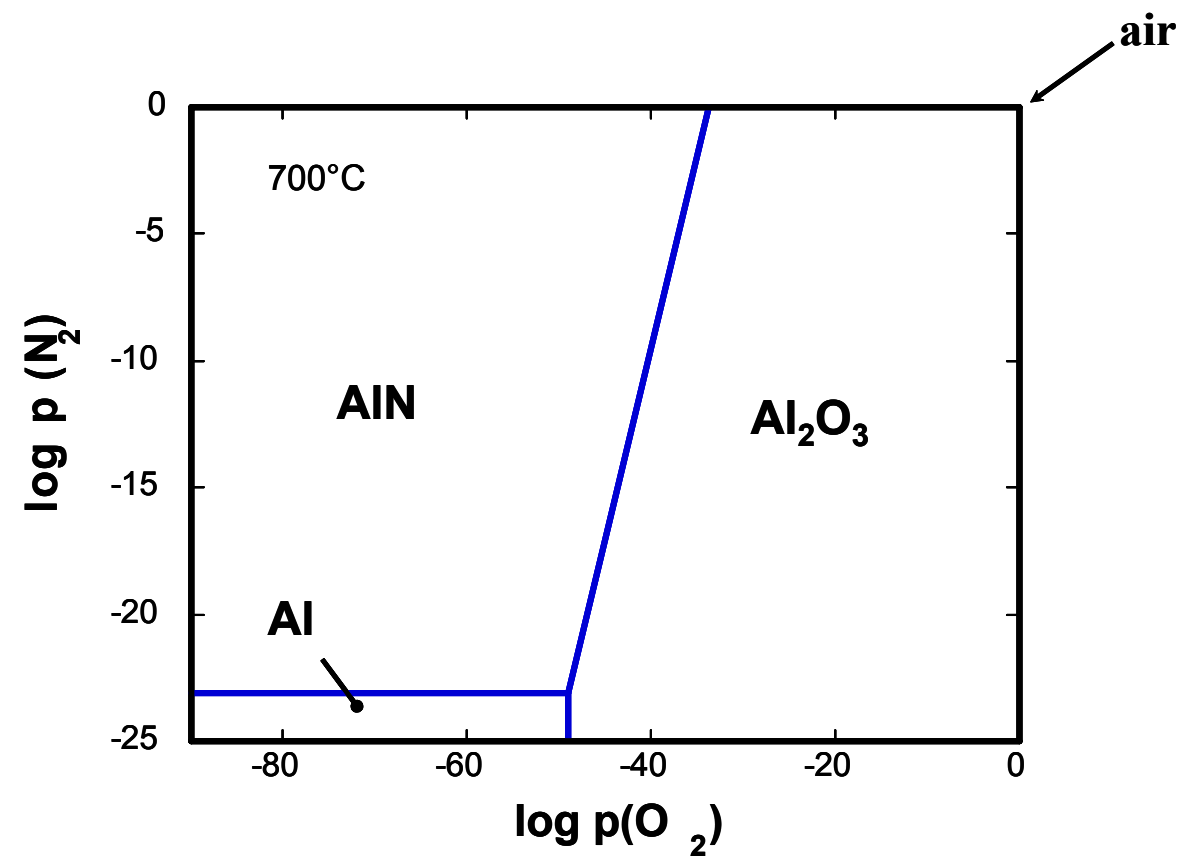

Fig 4.7: Computed equilibrium diagram for the $\mathrm{Al} / \mathrm{Al}_{2} \mathrm{O}_{3} / \mathrm{AlN}$ system at $700^{\circ} \mathrm{C}$ and low $p\left(\mathrm{O}_{2}\right)$ and $p\left(\mathrm{~N}_{2}\right)$. 
The AlN layer described above was always observed between, or adjacent to, $\mathrm{Al}_{2} \mathrm{O}_{3}$ (Fig 4.5). Thermochemical calculations (Fig 4.7) showed that $\mathrm{AlN}$ and $\mathrm{Al}_{2} \mathrm{O}_{3}$ can exist in equilibrium over a wide range of nitrogen partial pressures, $p\left(\mathrm{~N}_{2}\right)$, but only at low partial pressures of oxygen, $p\left(\mathrm{O}_{2}\right)$. Consequently, AIN formation must occur where the $p\left(\mathrm{O}_{2}\right)$ is locally reduced by reaction with the metallic $\mathrm{Al}$ in the interior of the melt. Therefore, the microstructural observations that AlN is always in contact with $\mathrm{Al}_{2} \mathrm{O}_{3}$ is consistent with what is expected from simple thermodynamic considerations.

Others have observed AIN in metal dross samples.[1,2] Its formation was attributed to overheating caused by the thermal insulating effect of the outer dross layer. No microstructural characterization of the AlN was given, so a direct comparison to the present findings cannot be made. However, the thermodynamic considerations for the formation of AlN described above should still apply.

The formation of significant amounts of $\mathrm{Al}_{2} \mathrm{O}_{3}$ was expected for the dross formed on alloy 1350 since it contains no $\mathrm{Mg}$. Previous work has shown that amorphous $\mathrm{Al}_{2} \mathrm{O}_{3}$ forms first followed by the nucleation of $\alpha-\mathrm{Al}_{2} \mathrm{O}_{3}$ within the first-grown amorphous $\mathrm{Al}_{2} \mathrm{O}_{3}$ film.[8-10] The additional formation of AlN and its clear morphological relationship with $\mathrm{Al}_{2} \mathrm{O}_{3}$, however, does not appear to have been previously reported. The amount of $\alpha-\mathrm{Al}_{2} \mathrm{O}_{3}$ and AlN that form on a pure alloy, such as 1350 , will depend on several factors including heating/melting temperature and residence (holding) time at temperature.[2,4,7] In general, both of these factors should be as low as possible to minimize the extent of dross $\left(\alpha-\mathrm{Al}_{2} \mathrm{O}_{3}\right)$ formation. It has also been observed that the $\alpha-\mathrm{Al}_{2} \mathrm{O}_{3}$ forms a network of oxide stringers that encapsulate $\mathrm{Al}$ metal and isolates it from the rest of the melt $[2,4,11]$ in a similar manner to that observed in this study, where the layered a- $\mathrm{Al}_{2} \mathrm{O}_{3} / \mathrm{AlN} / \alpha-\mathrm{Al}_{2} \mathrm{O}_{3}$ forms a closed membrane around the molten $\mathrm{Al}$ metal (see Fig 4.3). In order to recover the $\mathrm{Al}$ metal, it is necessary to free the $\mathrm{Al}$ metal from the network. However, this can be quite difficult. Thin oxide skins have a high tearing strength and can retain up to 20 times their weight in $\mathrm{Al}$ metal.[4] The present work indicates that the presence of an $\mathrm{AlN}$ layer next to the $\mathrm{Al}_{2} \mathrm{O}_{3}$ could affect the rigidity of the network. While a resistance to tearing (or breaking) of the surrounding oxide offers more protection against further oxidation, this type of microstructure will clearly trap more metal and make full metal recovery less likely.

4.3.2 Alloy 3004 (low Mg) - The surface dross layer in alloy $3004 \# 1$ (melt temperature $\sim 780^{\circ} \mathrm{C}$ ) consisted of a network of isolated dross particles. A low magnification image of a typical dross particle from Al alloy $3004 \# 1$ is shown in Fig 4.8. It was $\sim 1 \mathrm{~cm}$ in diameter/length and exhibited the characteristics typical of the Al metal encapsulation described for alloy 1350 (areas of trapped Al metal are denoted by arrows in Fig 4.8). Microstructural examination and X-ray diffraction of the dross particles identified cubic $\mathrm{MgO}$ as the primary (major) phase and $\mathrm{MgAl}_{2} \mathrm{O}_{4}$ spinel as the minor one. Crystalline $\alpha-\mathrm{Al}_{2} \mathrm{O}_{3}$ was not found. However, a- $\mathrm{Al}_{2} \mathrm{O}_{3}$ was identified by EPMA and this phase had a similar structure to the amorphous $\mathrm{Al}_{2} \mathrm{O}_{3}$ found in the alloy 1350 dross, as shown in Fig 4.9 (compare with Fig 4.4). All three phases, $\mathrm{a}-\mathrm{Al}_{2} \mathrm{O}_{3}, \mathrm{MgO}$, and $\mathrm{MgAl}_{2} \mathrm{O}_{4}$, were intermixed (Fig 4.9) and formed a network surrounding $\mathrm{Al}$ metal. It has been previously reported that, for $\mathrm{Mg}$-containing alloys, amorphous $\mathrm{Al}_{2} \mathrm{O}_{3}$ forms first and crystalline $\mathrm{MgO}$ nucleates within the amorphous $\mathrm{Al}_{2} \mathrm{O}_{3}$. [8-10] After $\mathrm{MgO}$ forms, the reaction of $\mathrm{MgO}$ and $\mathrm{Al}_{2} \mathrm{O}_{3}$ results in the formation of the spinel.[8-10] The continued formation of $\mathrm{MgAl}_{2} \mathrm{O}_{4}$ results in extremely rapid oxidation rates and, thus, extensive dross formation for these alloys. This is termed breakaway oxidation [10] and it will continue at an accelerated rate until the $\mathrm{Mg}$ near the surface of the melt has been depleted. At that point, the much slower oxidation of the molten $\mathrm{Al}$ to form $\alpha-\mathrm{Al}_{2} \mathrm{O}_{3}$ begins. Clearly, breakaway oxidation has not occurred in this alloy since the amount of spinel identified in the dross is minimal compared to the amounts of $\mathrm{a}-\mathrm{Al}_{2} \mathrm{O}_{3}$ and $\mathrm{MgO}$. 


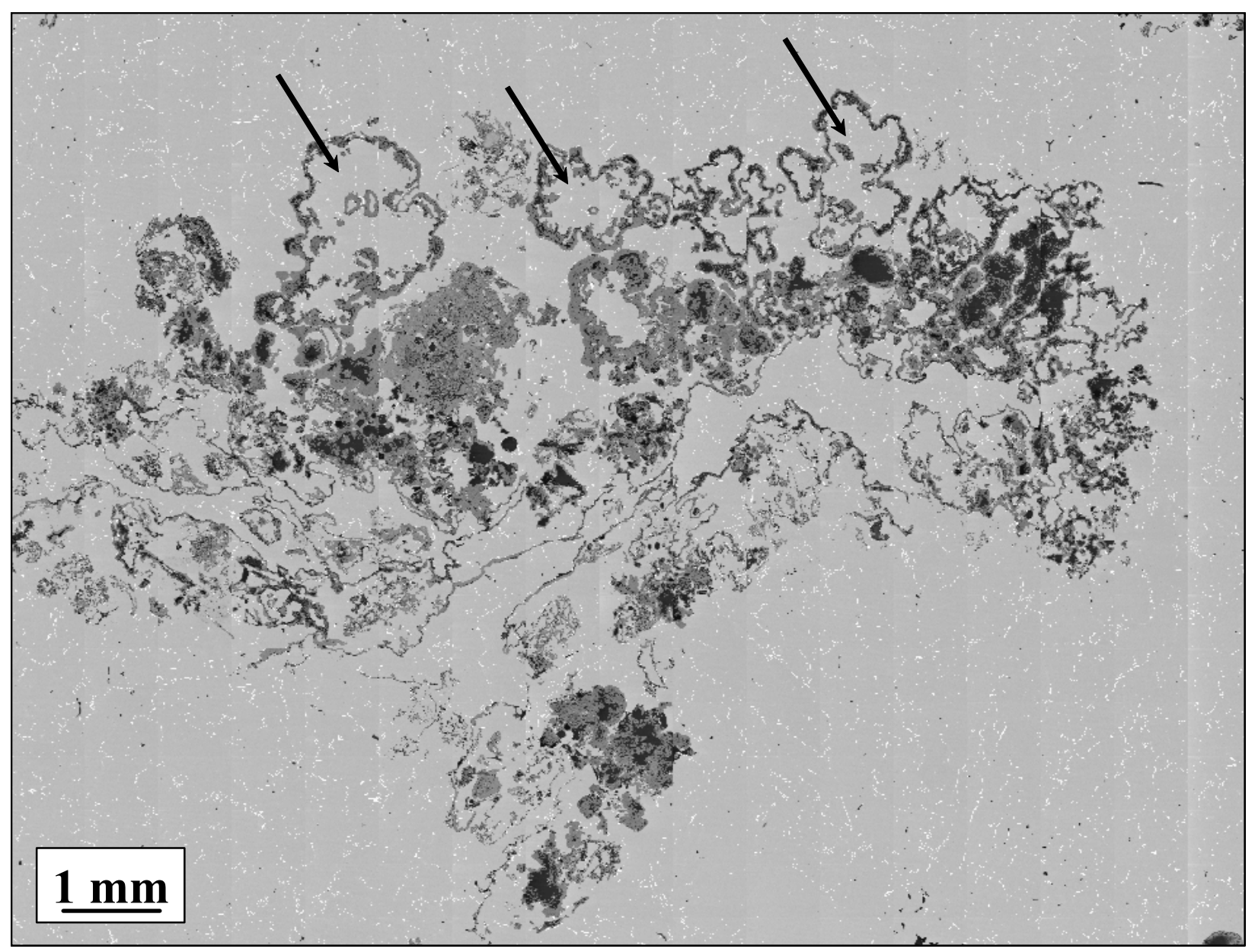

Fig 4.8: Dross particle from surface of molten 3004 \#1 (arrows denote trapped Al metal).

The surface dross layer in alloy $3004 \# 2$ (melt temperature $690^{\circ} \mathrm{C}$ ) was much thicker than that collected from $3004 \# 1$. This layer from $3004 \# 2$ was $\sim 7-8 \mathrm{~cm}$ thick and was much more fragmented compared with the isolated, self-contained particles observed in the dross from alloy 3004 \#1. A low magnification image showing the distribution of particles within the dross layer is shown in Fig 4.10 (compare with oxide particle morphology shown in Figure 4.8). The primary phase of the stringers found throughout the dross layer was $\mathrm{MgAl}_{2} \mathrm{O}_{4}$. The $\mathrm{MgAl}_{2} \mathrm{O}_{4}$ phase was identified using EPMA compositional analysis and $\mathrm{X}$-ray diffraction. A BSE image with associated elemental maps for $\mathrm{Mg}$ and $\mathrm{Al}$ is shown in Fig 4.11. There was no microstructural evidence for a- $\mathrm{Al}_{2} \mathrm{O}_{3}$ or crystalline $\mathrm{MgO}$ in this dross, only $\alpha-\mathrm{Al}_{2} \mathrm{O}_{3}$ and $\mathrm{MgAl}_{2} \mathrm{O}_{4}$ were identified. Needle-like $\alpha-\mathrm{Al}_{2} \mathrm{O}_{3}$ particles were associated with the $\mathrm{MgAl}_{2} \mathrm{O}_{4}$, as shown in Fig 4.12. X-ray diffraction data indicated that $\mathrm{MgAl}_{2} \mathrm{O}_{4}$ was the predominant phase in the dross collected from alloy $3004 \# 2$ and that $\alpha-\mathrm{Al}_{2} \mathrm{O}_{3}$ was a minor oxide constituent in the dross, as can be inferred from Fig 4.12. 


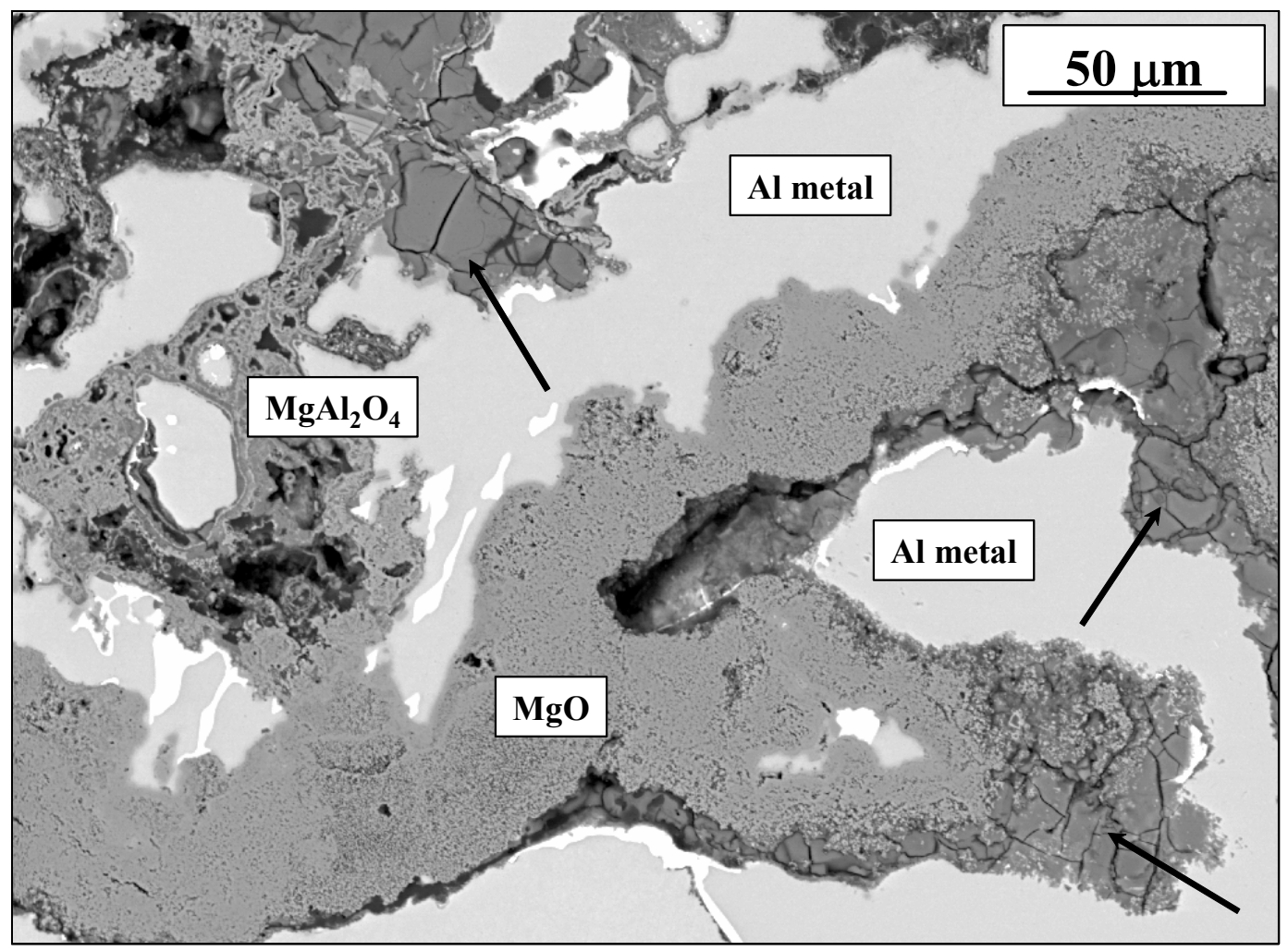

Fig 4.9: $\mathrm{BSE}$ image showing distribution of three phases, $a-\mathrm{Al}_{2} \mathrm{O}_{3}$ (shown by arrows), $\mathrm{MgO}$, and $\mathrm{MgAl}_{2} \mathrm{O}_{4}$ identified in dross from $3004 \# 1$.

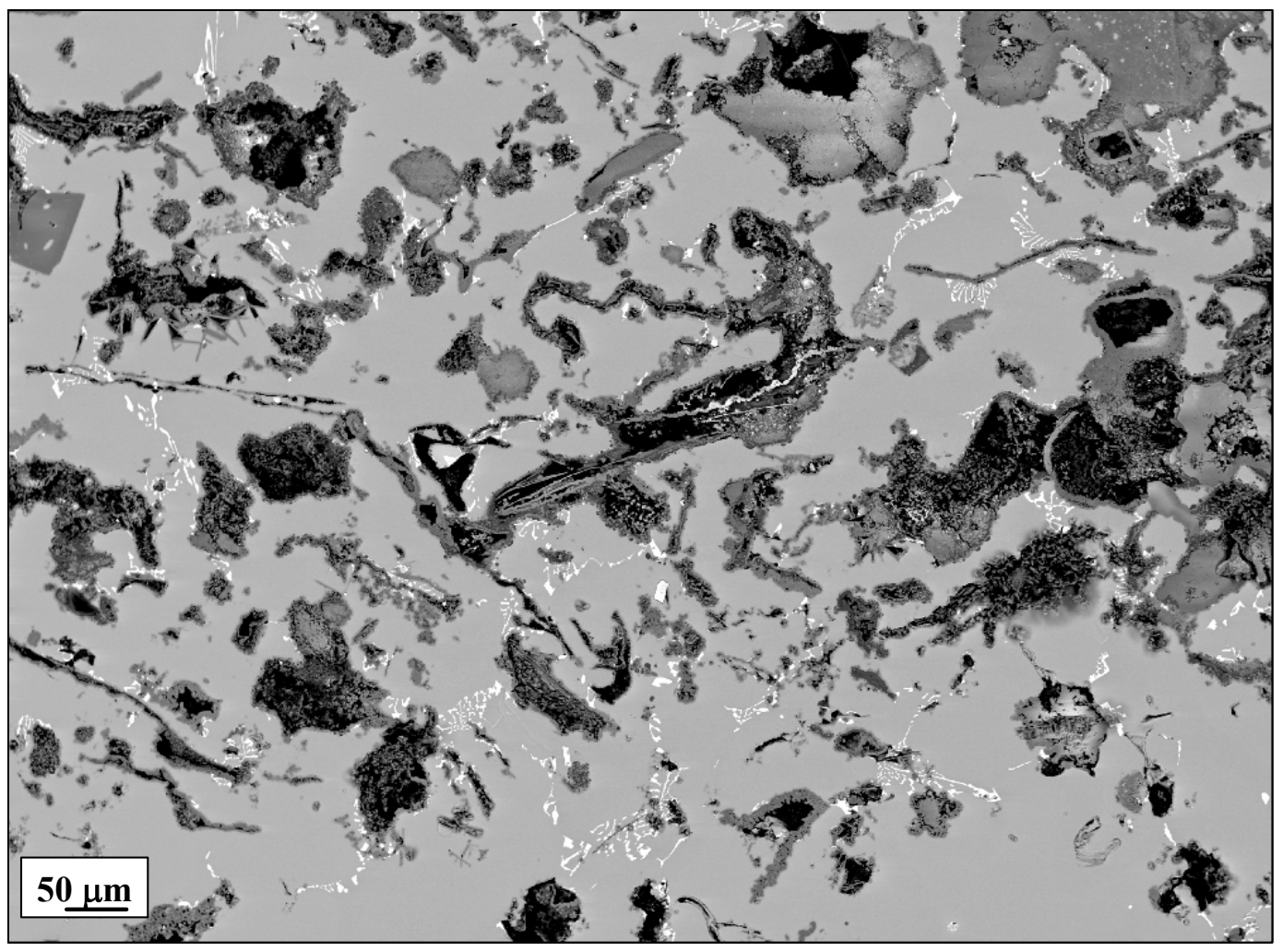

Fig 4.10: BSE image showing fragmented oxide particles within dross layer collected from 3004 \#2. 


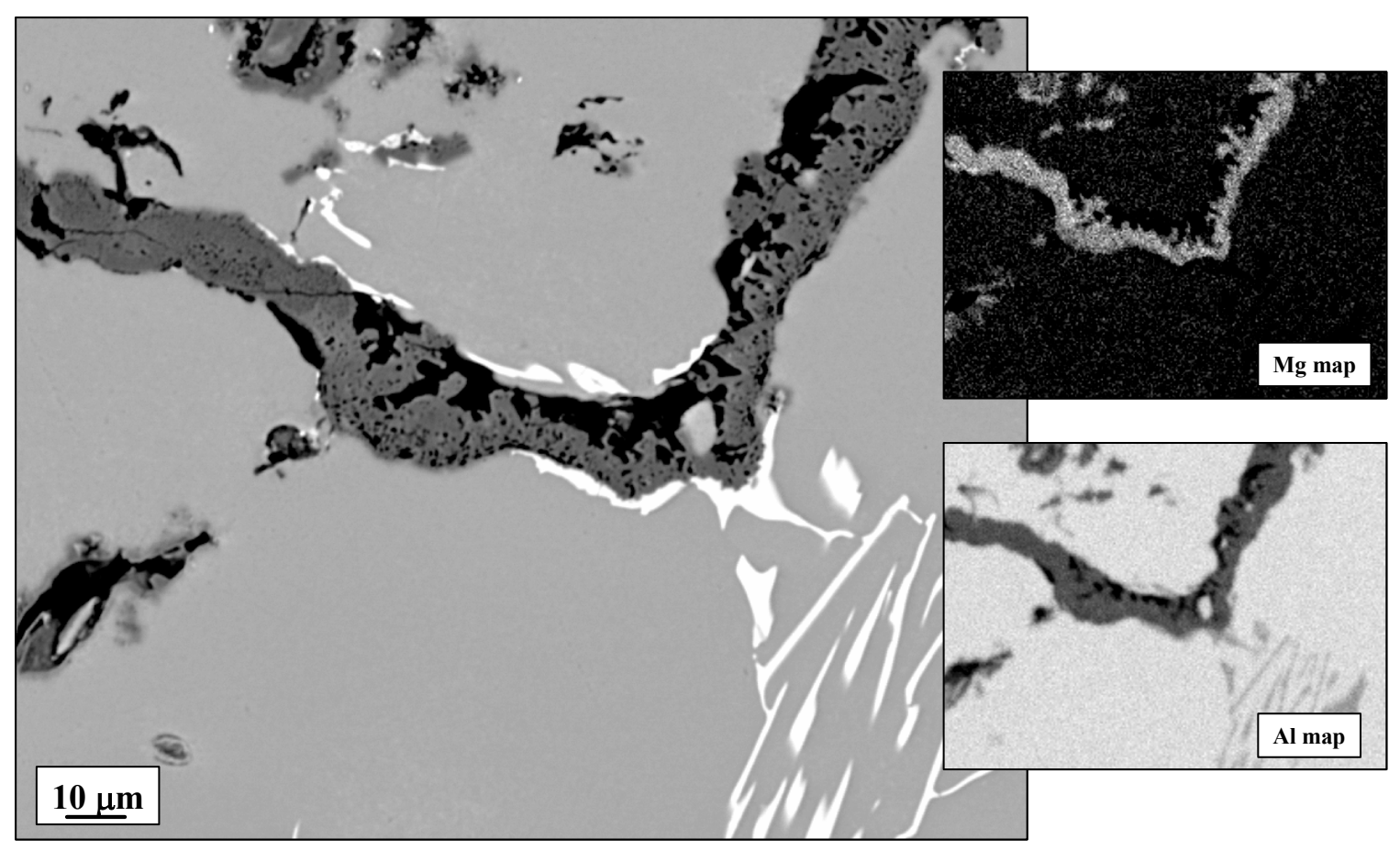

Fig 4.11: BSE image of fragmented $\mathrm{MgAl}_{2} \mathrm{O}_{4}$ phase in dross layer from alloy $3004 \# 2$

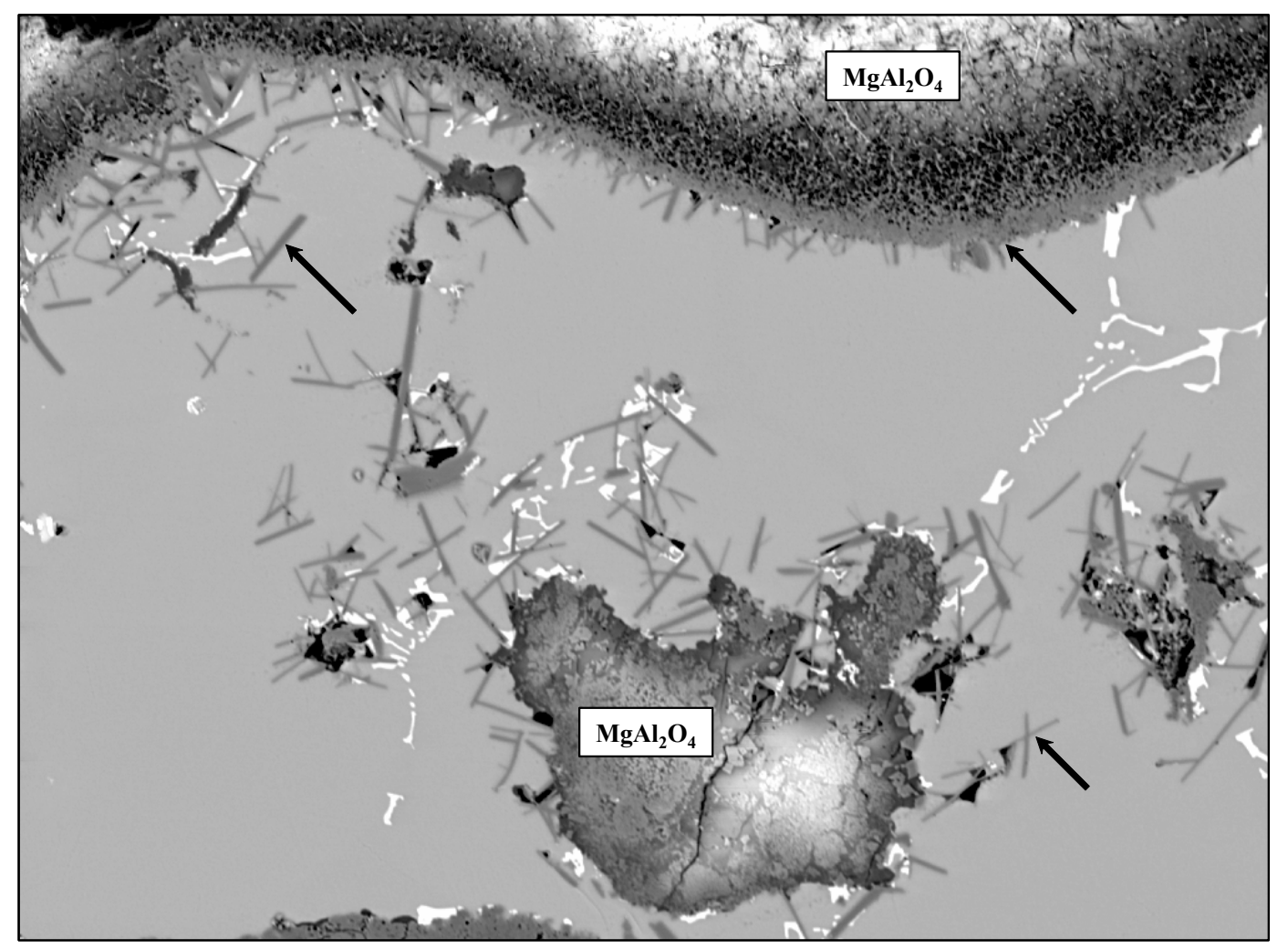

Fig 4.12: $\mathrm{BSE}$ image of $\mathrm{MgAl}_{2} \mathrm{O}_{4}$ phase \& a- $\mathrm{Al}_{2} \mathrm{O}_{3}$ needle-like phase (arrows) in dross - alloy $3004 \# 2$ 
As in the case with the dross collected from alloy $3004 \# 1$, the microstructural development and phases present within the dross are key indicators for the extent of oxidation of the alloy. The amount of dross present at the surface of alloy $3004 \# 1$ was not as extensive as that observed for $3004 \# 2$ and only small amounts of $\mathrm{MgAl}_{2} \mathrm{O}_{4}$ were found in the 3004 \#1dross. However, breakaway (very rapid) oxidation was observed for the dross collected from alloy $3004 \# 2$, as indicated by the significant amounts of $\mathrm{MgAl}_{2} \mathrm{O}_{4}$ (and lack of a- $\mathrm{Al}_{2} \mathrm{O}_{3}$ and $\mathrm{MgO}$ ) as well as the formation of $\alpha-\mathrm{Al}_{2} \mathrm{O}_{3}$. The spinel forms as a result of the reaction between $\mathrm{a}-\mathrm{Al}_{2} \mathrm{O}_{3}$ and $\mathrm{MgO}$, the first and second-formed oxides.[8-10] When all the local $\mathrm{Mg}$ is depleted near the surface of the melt, the accelerated oxidation associated with significant $\mathrm{MgAl}_{2} \mathrm{O}_{4}$ formation and oxidation of the $\mathrm{Al}$ metal to form $\alpha-\mathrm{Al}_{2} \mathrm{O}_{3}$ begins. [8-10] This is exactly the progression of microstructure/phase development observed in the dross from alloy $3004 \# 2$. Clearly, even in a low-Mg alloy such as 3004, oxidation of the molten $\mathrm{Al}$ is controlled by the rate at which the $\mathrm{Mg}$ is oxidized and thus consumed.

The $\mathrm{Al}$ metal melt temperatures at which the dross samples from alloy 3004 were collected were $780^{\circ} \mathrm{C}$ and $690^{\circ} \mathrm{C}$ for $3004 \# 1$ and $3004 \# 2$, respectively. The melt temperature and holding time play critical roles in determining the amount of oxidation of the alloy and, thus, it was expected that the degree of oxidation for 3004 \#2 would be less than that observed for 3004 \#1 since the melt temperature was less. The opposite was observed and there are several possible explanations for this observation. First, since a portion of the charge used for 3004 \#2 was actually the molten Al from alloy 3004 \#1, pre-existing oxides were likely present in the molten $3004 \# 1$. Additional oxidation likely occurred in the transport crucible as well as during pouring of the molten metal into the re-melt furnace used for alloy $3004 \# 2$. Second, the charge for the reverberatory re-melt furnace used for alloy 3004 \#1 was mixed in a side bay and, thus, most of the dross that formed remained in the side bay. The charge mix used for melting alloy $3004 \# 2$ was dropped directly into the furnace and, while the exact charge mix was unknown, a large fraction of the charge consisted of coil and other types of high surface area scrap. High surface area scrap will have a higher concentration of surface (pre-existing) oxides which will contribute to (increase) the amount of dross that forms.[2,4,6] Thus, even though the melting temperature was significantly lower for alloy $3004 \# 2$, there were other factors contributing to the observed accelerated rates of oxidation and excessive dross formation for this alloy sample.

The fragmented dross observed within the dross layer for alloy 3004 \#2 (Fig 4.10) compared to the isolated, self-contained dross particles formed at the surface of alloy 3004 \#1 (Fig 4.8) can be explained in terms of the amount and type of phases that formed in the dross. It has been observed in previous studies that during the re-melting of Al-Mg alloys, a protective oxide layer does not form when spinel forms at the expense of $\mathrm{MgO}$ and $\mathrm{a}-\mathrm{Al}_{2} \mathrm{O}_{3}$. Excessive stress is generated during the accelerated reaction between $\mathrm{MgO}$ and a- $\mathrm{Al}_{2} \mathrm{O}_{3}$ and increased amounts of $\mathrm{MgAl}_{2} \mathrm{O}_{4}$ form with increased holding time until the local Mg is depleted.[8-10] The stresses generated during these phase transformations in the melt will cause the oxide films to fracture and accelerated (breakaway) oxidation will continue as trapped Al is released. In the case of alloy $3004 \# 2$, there was less trapped Al but increased oxide formed. Since the formation of $\mathrm{MgAl}_{2} \mathrm{O}_{4}$ was not pronounced in alloy $3004 \# 1$, much less stress build-up occurred and the oxide films surrounded and encapsulated much more Al metal instead of breaking apart.

4.3.3 Alloy 5182 (high Mg) - The dross specimen was collected from molten alloy 5182 at $695^{\circ} \mathrm{C}$. The dross layer was relatively thick, $7-10 \mathrm{~cm}$, and was densely packed with small, fragmented oxide(s), as shown in Fig 4.13. Both X-ray diffraction and EPMA showed that $\mathrm{MgAl}_{2} \mathrm{O}_{4}$ was the only phase within the dross layer. Unlike the dross collected from alloy 3004 \#1, there were no large residual regions of a$\mathrm{Al}_{2} \mathrm{O}_{3}$ observed in the dross formed on alloy 5182; only spinel stringers similar to those found in the 3004 \#2 dross were identified (Fig 4.14). The amount of $\mathrm{MgAl}_{2} \mathrm{O}_{4}$ within the dross layer was significantly greater in that from alloy 5182 than the dross from alloy 3004 \#2. 


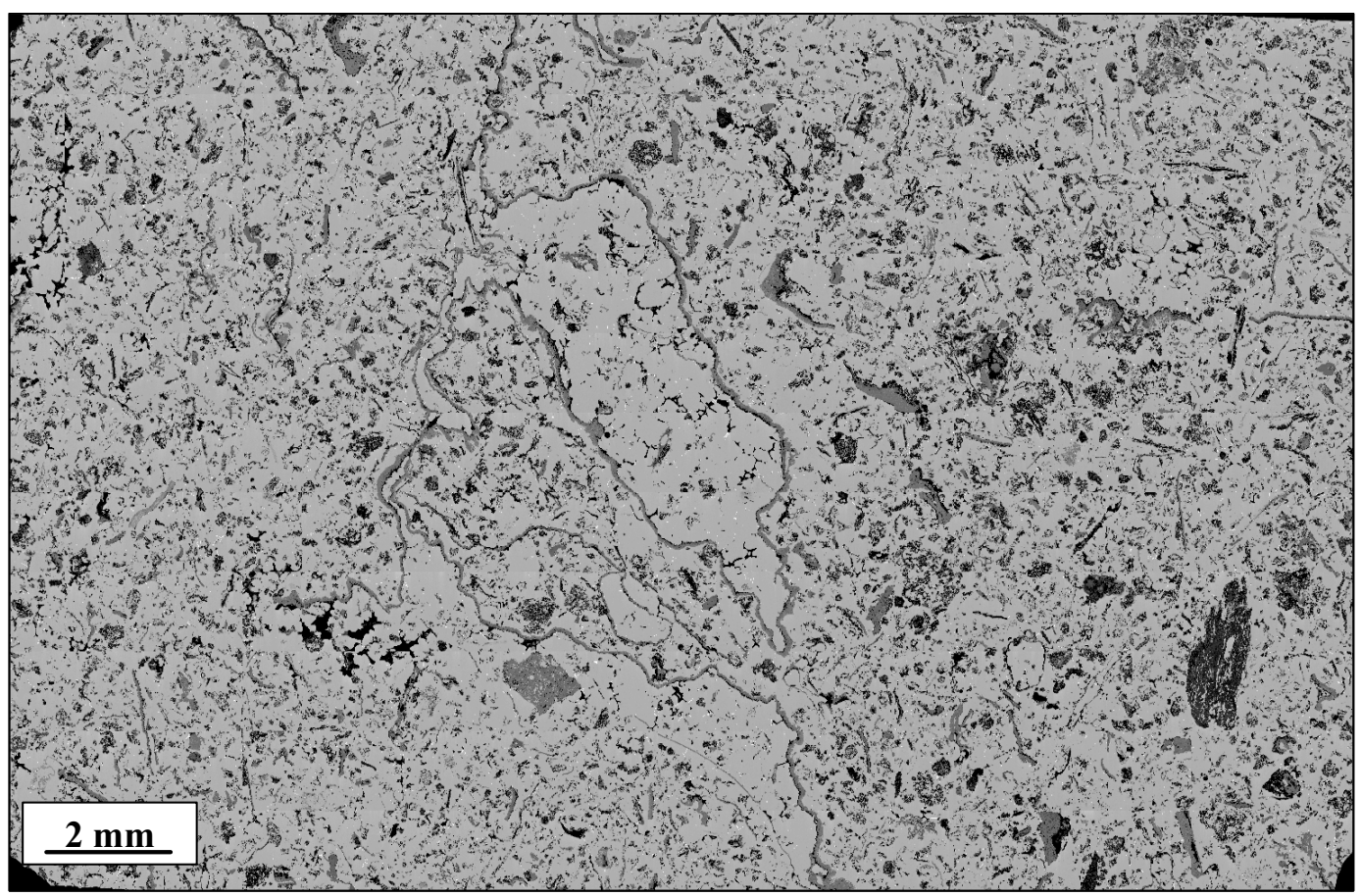

Fig 4.13: Low magnification BSE image of fragmented dross particles in dross layer from alloy 5182.

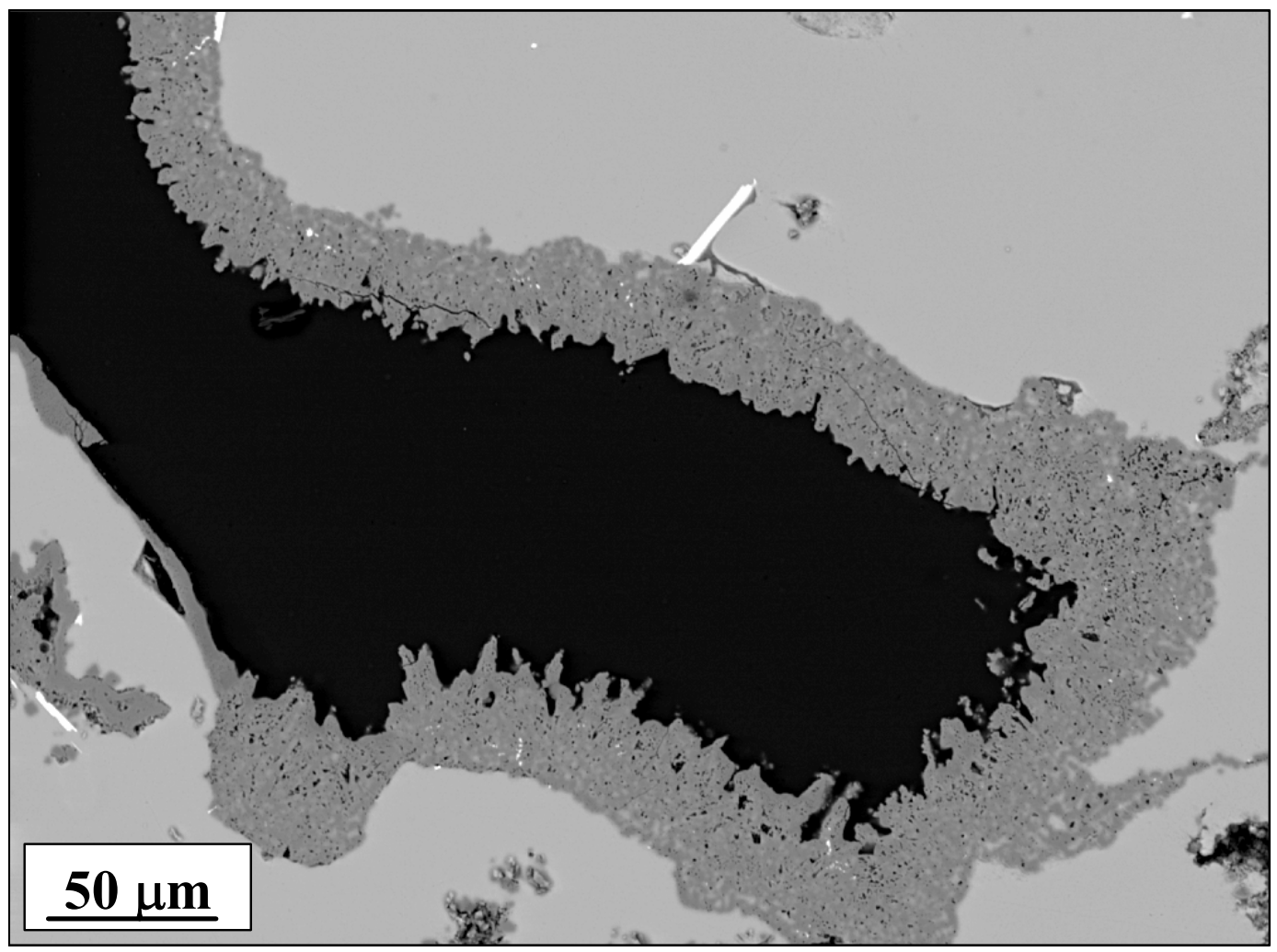

Fig 4.14: BSE image of typical $\mathrm{MgAl}_{2} \mathrm{O}_{4}$ phase in dross layer from alloy 5182 
The observation that $\alpha-\mathrm{Al}_{2} \mathrm{O}_{3}$ was not found within the 5182 dross layer was clearly a function of the amount of $\mathrm{Mg}$ present in the molten alloy. Alpha- $\mathrm{Al}_{2} \mathrm{O}_{3}$ only forms when the local $\mathrm{Mg}$ is fully consumed during the formation of $\mathrm{MgAl}_{2} \mathrm{O}_{4}$.[8-10] In the case of alloy $3004 \# 2$, the formation of $\mathrm{MgAl}_{2} \mathrm{O}_{4}$ was completed earlier because the amount of $\mathrm{Mg}$ in the alloy was much less than in alloy 5182. Thus, when the $\mathrm{Mg}$ was depleted at the surface of alloy $3004 \# 2$, the oxidation of the molten $\mathrm{Al}$ alloy proceeded by the much slower oxidation of the aluminum to $\alpha-\mathrm{Al}_{2} \mathrm{O}_{3}$. In the case of alloy 5182, which had at least 4 times as much $\mathrm{Mg}$ as 3004, breakaway oxidation of the alloy (rapid formation of $\mathrm{MgAl}_{2} \mathrm{O}_{4}$ ) continued for much longer times since a larger reservoir of $\mathrm{Mg}$ was available. At the time the dross specimen was collected from the surface of alloy 5182, the Mg content at the surface of the alloy had not yet been depleted. Thus, the amount of spinel was still increasing in the dross layer and the point had not yet been reached where oxidation of the less reactive aluminum was predominant. However, no a- $\mathrm{Al}_{2} \mathrm{O}_{3}$ or $\mathrm{MgO}$ were identified in the 5182 dross either, possibly indicating that the $\mathrm{MgAl}_{2} \mathrm{O}_{4}$ formation within the dross layer was nearly completed at the time the dross specimen was collected.

4.3.4 Oxidation Sequence and Time to Breakaway The results presented herein are very consistent with those reported by Cochran, et al., for laboratory exposures of Al containing 1-14\% Mg.[10] In that work, the phases formed as a function of $\mathrm{Mg}$ content and time were described (although the primary focus of the study was on the effect of furnace atmosphere and additives on the onset of $\mathrm{MgAl}_{2} \mathrm{O}_{4}$ formation). Cochran et al.[10] summarized their findings by plotting an estimate of the amount of oxide formed versus time at temperature. This plot is reproduced as part of Fig 4.15 to illustrate that the present Al dross samples collected from the different re-melt furnaces nicely fall on the Cochran et al. curve. The placement of the three Mg-containing alloys on the curve in Fig 4.15 was determined by the measured phase content and extent of oxidation. As in previous work,[8-10] a breakaway oxidation regime associated with spinel formation is clear from the present dross analyses. Thus, controlling extensive dross accumulation should be focused on the suppression of the formation of $\mathrm{MgAl}_{2} \mathrm{O}_{4}$ or stabilization of the $\mathrm{a}-\mathrm{Al}_{2} \mathrm{O}_{3}$ and/or $\mathrm{MgO}$.

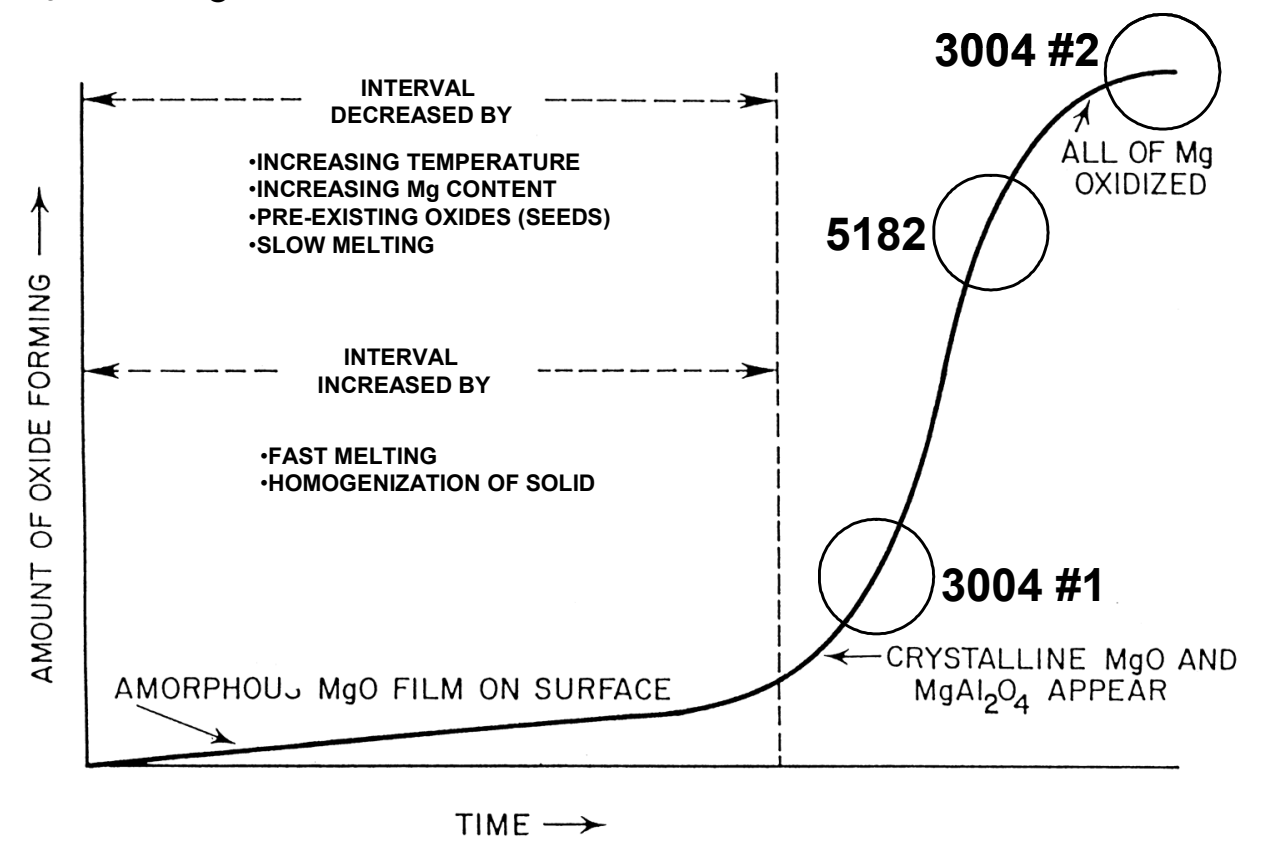

Fig 4.15: Amount of oxide formed vs. time plot for Al-Mg alloys (from Reference 10) with results from present work superimposed. 


\subsection{Summary}

Dross specimens were collected from the near-surface regions of industrial re-melt furnaces for three different $\mathrm{Al}$ alloys; 1350 (no Mg), 3004 (low Mg), and 5182 (high Mg). Bulk dross samples were collected using a standard protocol for each industrial furnace in order to directly compare the results. Extensive microstructural characterization was conducted on each dross specimen to determine oxide morphology and phase content. The phase content within the different dross specimens is summarized as follows:

- alloy 1350 (no $\mathrm{Mg}$ ) - layered a- $\mathrm{Al}_{2} \mathrm{O}_{3} / \mathrm{AlN} / \alpha-\mathrm{Al}_{2} \mathrm{O}_{3}$ structure

- alloy $3004 \# 1$ (low $\mathrm{Mg}$ ) - $\mathrm{MgO}$ (major) + a- $\mathrm{Al}_{2} \mathrm{O}_{3}$ (major) $+\mathrm{MgAl}_{2} \mathrm{O}_{4}$ (minor)

- alloy 3004 \#2 (low $\mathrm{Mg}$ ) $-\mathrm{MgAl}_{2} \mathrm{O}_{4}$ (major) $+\alpha-\mathrm{Al}_{2} \mathrm{O}_{3}$ (minor)

- alloy 5182 (high $\mathrm{Mg}$ ) - $\mathrm{MgAl}_{2} \mathrm{O}_{4}$

The progressive formation of the different phases provided qualitative estimates of the extent of oxidation and can also be related to the oxidation rate and amount of dross observed at the melt surface. When $\mathrm{MgAl}_{2} \mathrm{O}_{4}$ spinel forms within the dross layer of the Mg-containing alloys, a significant increase in the oxidation rate (breakaway oxidation) occurs until all the $\mathrm{Mg}$ is depleted in the surface region. At this point, oxidation of the less reactive molten $\mathrm{Al}$ metal dominates and the oxidation rate is reduced. The extensive formation of $\mathrm{MgAl}_{2} \mathrm{O}_{4}$ in the dross formed on alloy $3004 \# 2$ and alloy 5182 resulted in a fragmented oxide layer rather than the network of encapsulated Al within oxide stringers associated with the dross layer collected from alloy 1350 and alloy $3004 \# 1$. 


\section{Analysis of Molten Aluminum Alloy Surfaces (Task 5 and 7)}

\subsection{Introduction}

Laboratory studies of the mechanisms of dross formation were performed to complement and confirm the results of the microstructural characterization of industrial dross samples. Two types of experiments were performed. The first was a study using X-ray Photoelectron Spectroscopy (XPS), in which the surface of an oxidizing molten metal sample was analyzed for its chemical composition. The second was an X-raydiffraction (XRD) study at Argonne's Advanced Photon Source that identified the crystalline phases that formed during the initial stages of molten aluminum alloy oxidation.

\subsection{X-ray Photoelectron Spectroscopy}

$\mathrm{X}$-ray photoelectron spectroscopy (XPS) is a surface analysis technique based upon the photoelectric effect. In XPS, x-rays excite photoelectrons in surface atoms, and the emitted electron signal is plotted as a spectrum of binding energies. Spectral information is collected from a depth of 2-20 atomic layers. This technique is well suited to investigate the surface of molten aluminum alloys because aluminum has a low vapor pressure and experiments need to be performed in an ultra-high vacuum.

The experiments consisted of analyzing the clean surface of the molten aluminum alloy, then subjecting in to a known dose of oxygen, reanalyzing the surface. The procedure allowed for the determination of the surface oxide layer that forms initially on molten aluminum.

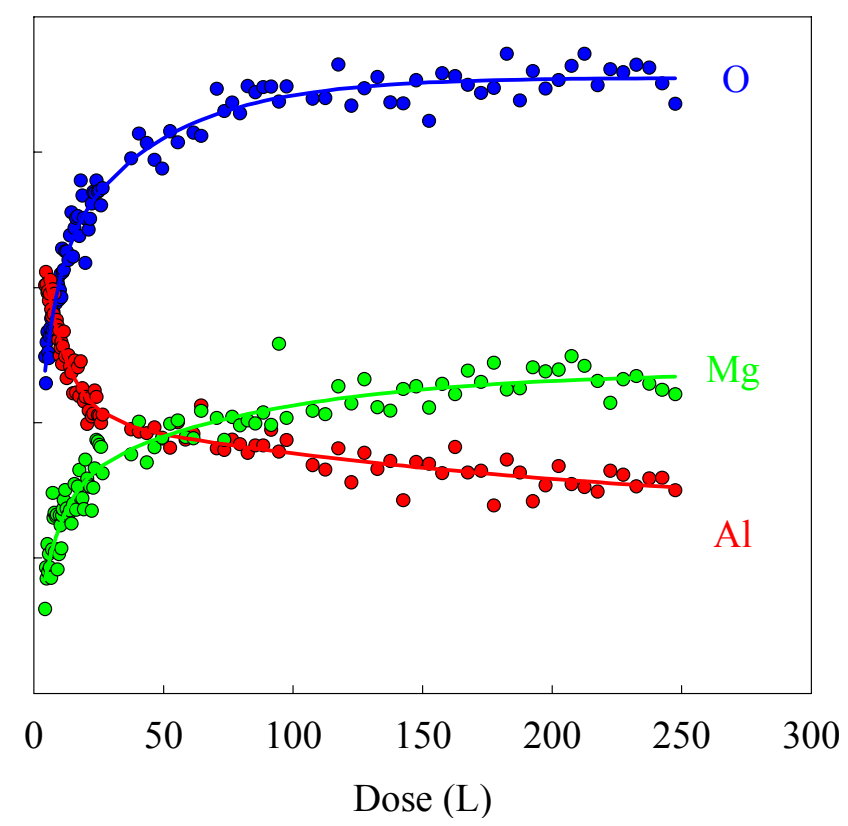

Fig 5.1: Relative concentration of $\mathrm{Al}, \mathrm{Mg}$, and $\mathrm{O}$ in the top few atomic layers of a molten high- $\mathrm{Mg}$ aluminum alloy (5182) as a function of added oxygen (dose) at $700^{\circ} \mathrm{C}$.

Several aluminum alloy samples (including 1350, 3004 and 5182) were analyzed by XPS. A typical result for alloy 5182 is shown Fig 5.1. The figure shows the presence of a thin aluminum oxide film prior to introduction of oxygen to the system. The concentration of alloy constituents (not shown) is negligible is comparison to the strength of the aluminum signal. However, the concentration of magnesium in the near surface region is almost $1 / 3$ the concentration of aluminum in the 5182 alloy. The bulk magnesium 
concentration in the 5182 alloy is $4.5 \mathrm{wt} \%$. This suggests that magnesium, and only magnesium, segregates to the molten aluminum alloy.

Furthermore, as oxygen is added to the molten alloy surface, the concentration of magnesium increases proportionally to oxygen. This suggests that magnesium oxide form of the surface, and magnesium metal from the bulk alloy continues to segregate to the oxide-metal interface.

The results of the XPS work support the observation in the industrial dross samples that indicates that magnesium oxide forms on the surface of a thin amorphous aluminum oxide layer, and continues to form until all the local magnesium content in depleted.

\subsection{X-ray Diffraction}

X-rays generated by Argonne's Advanced Photon Source (APS) were used to analyze the surface of a molten aluminum alloy sample. The focus was on a clean 5182 alloy surface, since this sample contained the greatest $\mathrm{Mg}$ concentration. Low-angle scattering of $\mathrm{x}$-rays diffracted off the molten alloy sample were collected and analyzed as a function of time during exposure of the alloy to air and oxygen atmospheres. The experiments were performed at APS at the BESSERC beamline. X-ray diffraction was used to measure the oxide film structure at the aluminum alloy surface held in a controlled environment (temperature and gas composition) as a function of time. The experiments consist of positioning a small amount of molten metal in an x-ray beam and measuring deflected x-rays. The APS hutch, sample holder and experimental set up are shown in Fig 5.2 and 5.3.

\subsection{Experimental}

A one-gram aluminum alloy sample was placed on a substrate within a metal foil spill pan (1-in $\left.{ }^{2}\right)$, and placed on the specimen heating stage. A quartz tube supported the stage. An outer quartz tube o-ringsealed to water-cooled aluminum end support defined the atmosphere-controlled chamber. Once assembled, the chamber was leak-tested and affixed to the APS Huber support structure. Cooling water was generated by a portable water cooler. The chamber was purged and pre-heated gas was introduced to the chamber. The specimen stage was powered up and heated to the desired temperature to observe oxide film growth. The hutch was closed and x-ray experiments began. At the conclusion of an experiment, the chamber was cooled, disassembled and the metal specimen and holder was replaced with the next one.
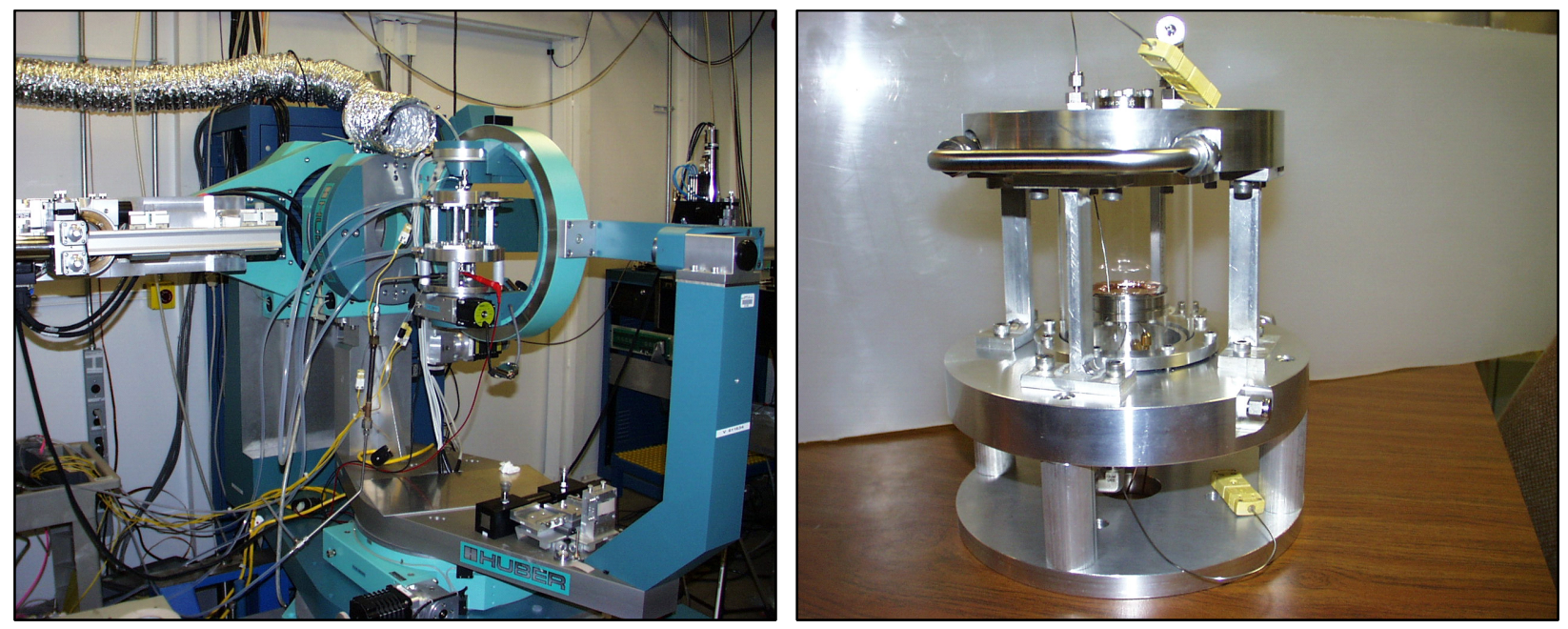

Fig 5.2: APS Hutch and sample holder. 


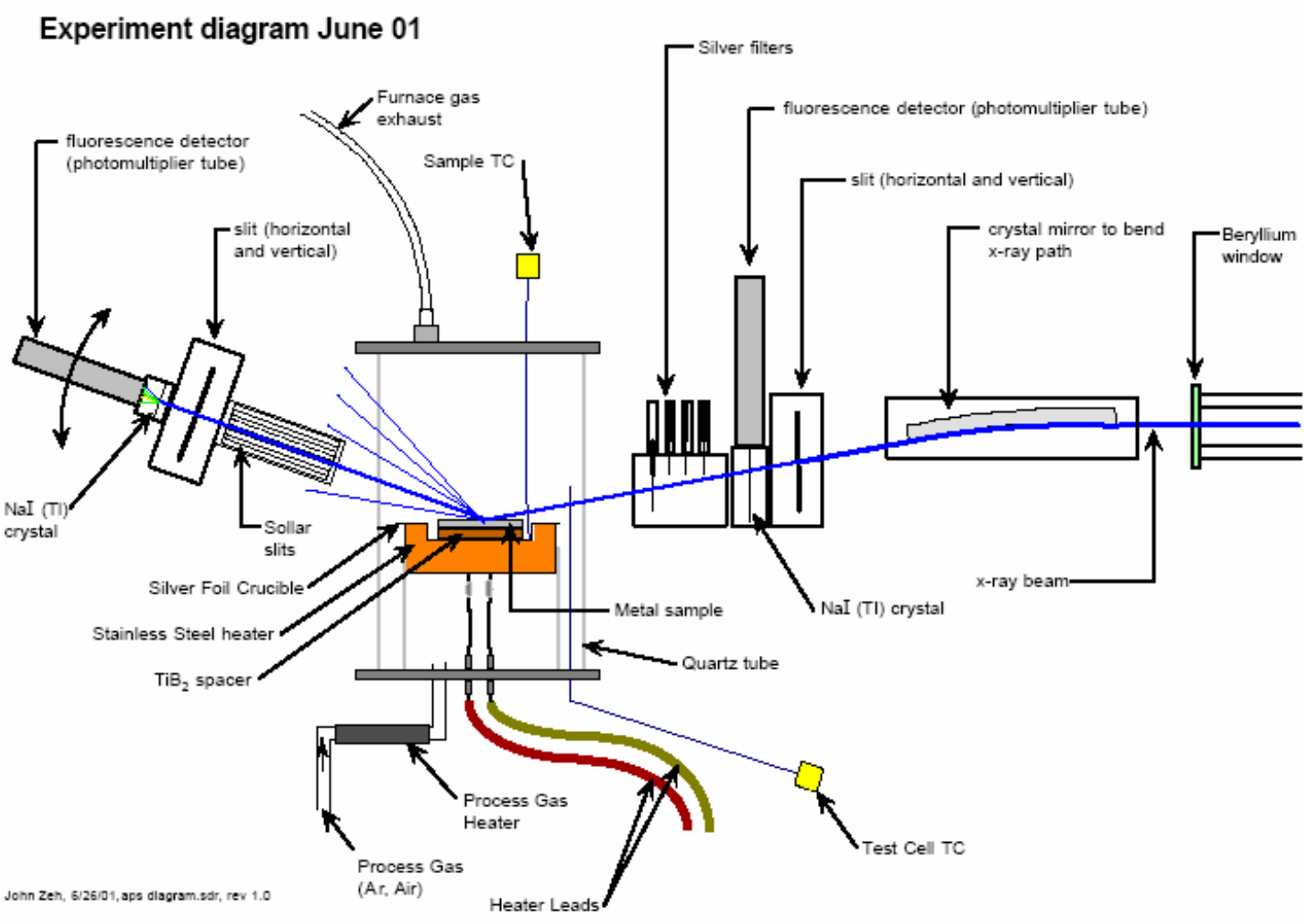

Fig 5.3: Schematic of experiment

\subsection{Results}

X-ray diffraction patterns of the oxidizing aluminum alloy samples were captured on a 2-dimentional collector every 60 seconds. Initially, the pattern contained only the broad band indicative of molten metal. As oxygen was added to the chamber, fine crystallites were detected at apparently random positions of the detector. As oxidation continued, a circular diffraction pattern began to emerge. By adjusting the elevation of the sample relative to the x-ray beam, it was possible to discern a thickness crystalline structure forming on the surface of the molten aluminum alloy sample. The patterns were compared to those of standard compound exposed under the same conditions, and it was determined that the patterns on the 5182 alloy surface were identical to those of magnesium oxide, and shown in Fig 5.4. This was the first direct in-situ determination of the structure of an oxide film growing on a molten aluminum alloy surface. 


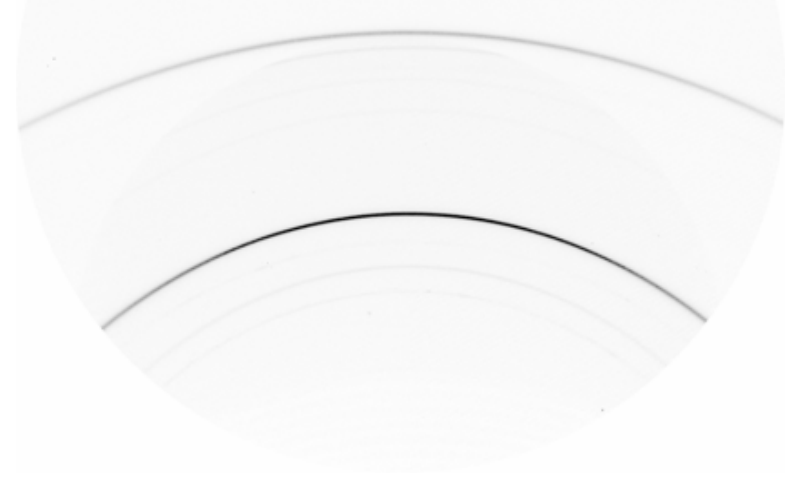

$\mathrm{MgO}$ standard

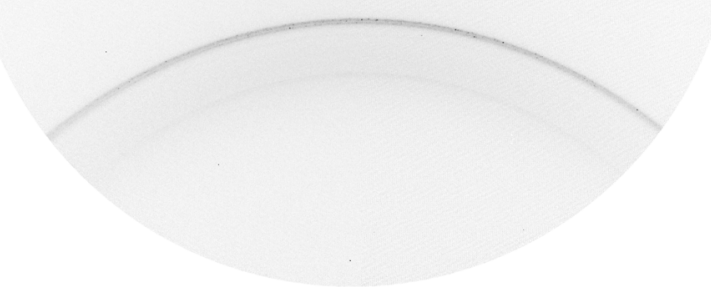

Alloy 5182

Fig 5.4: X-ray diffraction pattern of a magnesia standard compared to the initial structure that forms on a clean surface of molten high-Mg aluminum alloy (5182).

\subsection{Summary}

The analyses of the molten aluminum alloy surfaces that investigated the initial stages of molten aluminum oxidation were the first of their kind. The results clearly indicated that magnesium oxide is the first crystalline phase that forms on oxidizing aluminum, which always contains a very thin layer of amorphous layer of aluminum oxide. Since the gas phase in these experiments was oxygen, the presence of effect of aluminum nitride was not investigated. Nevertheless, whether the amorphous film in aluminum oxide or nitride, it does not appear to hinder magnesium surface oxidation. Magnesium segregates to the surface where it reacts with oxygen to form magnesium oxide. The experiments provide the first direct evidence of this reaction.

The basic science studies have a significant to industrial dross formation. While the importance of magnesium in dross formation was well known, as was the fact that alloys containing more magnesium tended to produce more dross, it has now been demonstrated that no element other than magnesium initiates dross formation in aluminum alloys that contain even modest amounts of magnesium. 


\section{Laboratory-Scale Reverberatory Furnace Development (Task 8, 9, 10 and 11)}

\subsection{Introduction}

Many efforts have been made to study and characterize dross formation and growth during secondary melting. [13] These studies typically fall into two categories, empirical studies of industrial furnaces [14, $15,16]$ or academic studies of aluminum melting furnaces in simulated environments on the bench top $[17,18]$. In this part of the project, a laboratory-scale direct-natural-gas-fired reverberatory furnace was developed at the Albany Research Center (ARC) to help evaluate melt-loss reduction concepts. The furnace could also allow industry to perform follow-on work to test key theoretical and empirical concepts concerning alloy composition and form, pool depth, bath agitation, furnace atmosphere and pressure, burner location and type, fuel input and heating rate, refractory interactions, etc. on the efficient operation of industrial units $[19,20]$. Charge materials and the effect of varying heating variables would also be studied independently. The furnace was designed to be cleaned thoroughly after each test and the composition of either product stream to be weighed and analyzed.

\subsection{Furnace Characteristics}

The ARC Laboratory Scale Reverberatory Furnace (LSRF) was designed to provide a reasonable approximation of larger direct-fired furnaces used in the secondary aluminum industry. Typical natural gas fired furnaces that are capable of melting $10-200$ pounds of aluminum are not suitable to study metal oxidation and energy consumption concerns because their melting mode is indirect. The combustion gases do not come in intimate contact with the aluminum in the same fashion as a direct-fired melting furnace. The ARC LSRF, while not a scale copy of any direct-fired natural gas melting system, provides direct contact of the aluminum charge to the hot gas products of natural gas combustion $\left(\mathrm{CO}_{2}\right.$, $\mathrm{CO}, \mathrm{O}_{2}, \mathrm{C}, \mathrm{H}_{2} \mathrm{O}, \mathrm{H}_{2}, \mathrm{SO}_{2}, \mathrm{NO}_{\mathrm{x}}$, and $\mathrm{N}_{2}$ ) in the same manner as might be seen in an industrial operation.

The furnace (Fig 6.1) was designed to separate into three, easy-to-service sections. The hearth/well holds the metal and provides an area for charging, skimming, and sampling of the aluminum while the furnace is in operation. The plenum area is where the single, high velocity natural gas flame is introduced to the furnace. The well and the plenum when bolted together comprise the main section of the furnace. The third section is the dampered exhaust. The damper can be used to adjust the furnace pressure. Because of this modular design, easy and complete clean up is possible after each test. All solids are recoverable to a tenth of a pound.

The burner is capable of outputs between 125,000 and $800,000 \mathrm{BTU} / \mathrm{hr}$. The furnace diameter is 17 inches with a bath depth of 10 inches, giving a well volume of $1.1 \mathrm{cu}$. $\mathrm{ft}$. The volume of the plenum is 2.2 $\mathrm{cu}$. $\mathrm{ft}$. The furnace is lined with approximately six inches of traditional ultra-low cement, $70 \%$ alumina refractory with anti-wetting agents. The well is also capable of accepting crucibles and liners while still melting in direct-fired mode. Although designed as a tap-out furnace, molten aluminum can be dipped from the furnace, or the molten pools can be solidified in place for sectioning and examination of areas of interest.

\subsection{Dross Formation}

$\mathrm{H}_{2} \mathrm{O}$ and $\mathrm{O}_{2}$ are the primary oxidants in a natural gas-fired furnace. Also, at high enough temperatures, nitrogen can also participate in the depletion of useful aluminum. The role each of these compounds plays on the oxidation of aluminum and the formation of dross is not well understood. Also, alloy constituents such as $\mathrm{Mg}, \mathrm{Si}, \mathrm{Mn}$, and $\mathrm{Li}$ have been known to attribute to oxide formation. This oxidation appears to increase as the temperature of the bath increases. Fig 6.2 shows an example of the difference between dross grown on a low Mg alloy melt (3004) and high $\mathrm{Mg}$ alloy melt (5182). 

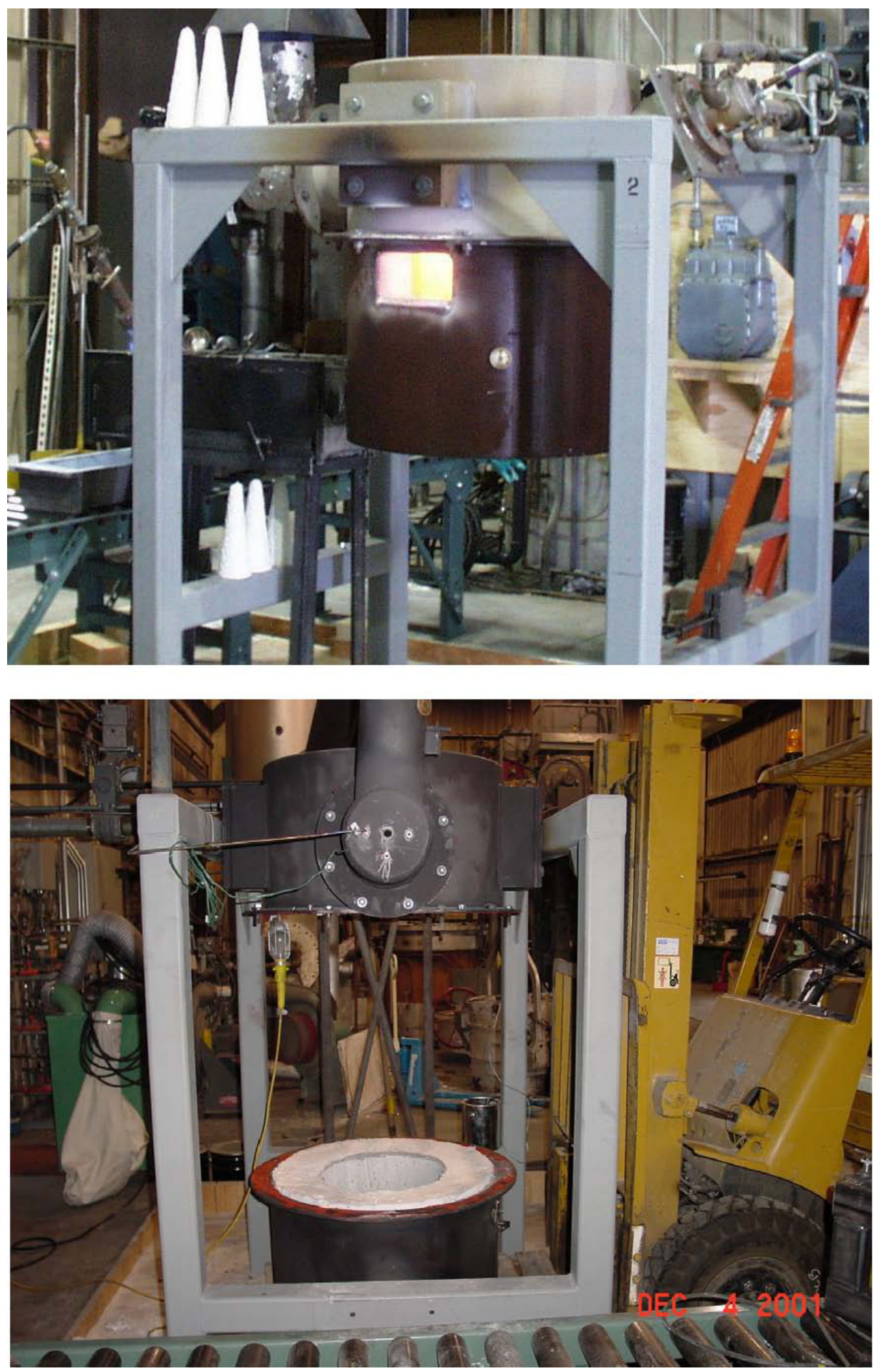

Fig 6.1: (Top) The ARC Laboratory Scale Reverb in operation during its inaugural heat. (Bottom) The ARC Laboratory Scale Reverb with the well and plenum sections separated in preparation for clean-up. 

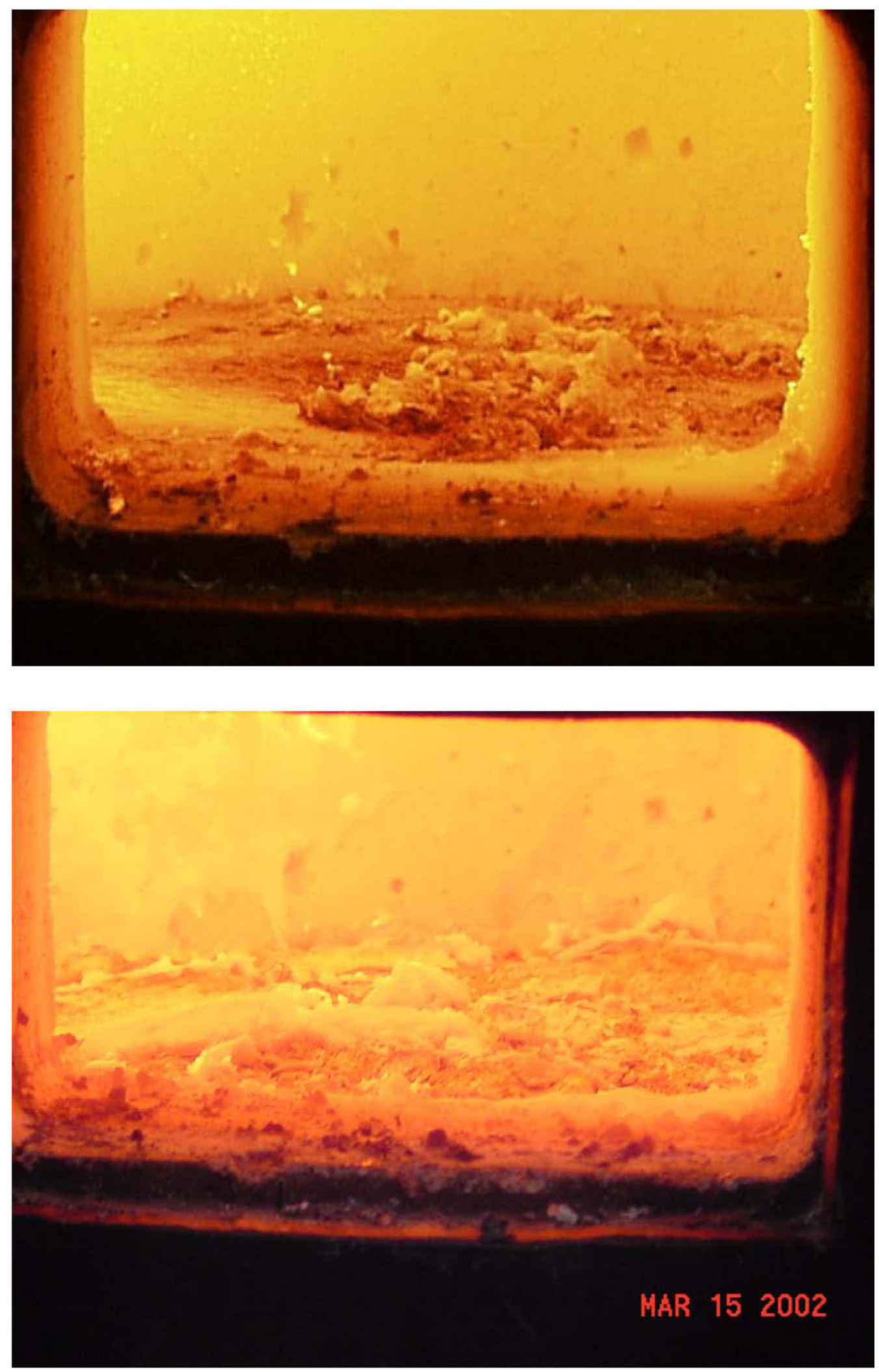

Fig 6.2: (Top) Dross formation on "prime" aluminum. (Bottom) Dross formation on Al-Mg-Mn Alloy Both pictures taken immediately after the bath was established, before initial skim. 
Simulated environments and small samples are a good approximation of the related phenomenon, but they cannot give justice to the larger scale issues of direct-fired natural gas melting. While the ARC LSRF was not developed as a scale model of any in particular, it does however, embody many of the critical factors of the industrial units. One key factor in reverberatory melting is that the plenum temperature is greater than the metal temperature. Another is that the typical temperature gradient present in unstirred molten metal bath is realized. 


\section{Development and Evaluation of Melt Loss Reduction Technology (Task 8, 9, 10 and 11)}

\subsection{Introduction}

Oxide growth can be limited by decreasing the melt surface exposure to furnace atmosphere.

This project was the $3^{\text {rd }}$ concept of a larger project investigating ways to reduce melt loss (or dross formation) in the secondary aluminum industry. The goal of this project is to determine the feasibility of using a physical barrier to cover a molten aluminum melt. This cover would reduce oxygen from reaching the melt surface, therefore reducing metal oxidation and the formation of dross. In addition, if the cover was more thermally conductive than the dross layer lower furnace temperatures would be required to maintain the melt temperature, further reducing dross growth. The scope of the project included identifying a suitable cover material, testing its effectiveness with bench scale tests and testing promising materials at Albany Research Center using their gas-fired experimental furnace. Future goals include industrial pilot testing and determining the optimal shape/configuration for industrial usage.

The initial stage of this research required identifying promising materials that could be used for a melt cover. This task proved more difficult that it initially seemed due to the extreme conditions the material would be required to endure. Temperatures could reach $1000^{\circ} \mathrm{C}$, there were chances of thermal shock and most importantly, the material had to withstand direct contact with molten aluminum and aluminum oxides. The material had to be non-wetting to molten aluminum and since molten aluminum tends to coat everything it comes in contact with it, it had to be easy to remove frozen metal from it.

In addition to the material being able to simply survive the harsh environment of aluminum melt; it also needed to have additional properties to be an effective as a melt cover. The material has to be highly thermally conductive. If the material was less thermally conductive than the various components of dross it would simply insulate the melt and not allow heat to penetrate the cover, requiring additional heat to keep the metal molten. It would be desirable if the material had a density less than or close to that of aluminum. This would allow the cover to float on the surface of the melt and not require special shapes to promote flotation. After a comprehensive search, a list of candidate materials was developed. Various components of dross were included with the table for comparison. (See Table 7.1)

\begin{tabular}{|c|c|c|c|c|}
\hline Material & Formula & $\begin{array}{l}\text { Thermal Conductivity } \\
(\mathrm{W} / \mathrm{mK})\end{array}$ & $\begin{array}{l}\text { Thermal Conductivity } \\
(\mathrm{W} / \mathrm{mK})\end{array}$ & \begin{tabular}{|l} 
Density \\
(g/cc)
\end{tabular} \\
\hline Aluminum (pure) & $\mathrm{Al}$ & $237 @ 25^{\circ} \mathrm{C}$ & $218 @ 530^{\circ} \mathrm{C}$ & 2.7 \\
\hline 5052 Alloy & & $137 @ 25^{\circ} \mathrm{C}$ & $?$ & 2.68 \\
\hline Titanium Diboride & TiB2 & $25-96 @ 25^{\circ} \mathrm{C}$ & $77.8 @ 1200^{\circ} \mathrm{C}$ & 4.5 \\
\hline Boron Nitride & $\mathrm{BN}$ & $23-121 @ 25^{\circ} \mathrm{C}$ & $27.0 @ 700^{\circ} \mathrm{C}$ (grade HP) & $2.27-3.49$ \\
\hline Aluminum Nitride & AlN & $80-200 @ 25^{\circ} \mathrm{C}$ & $20.06 @ 600^{\circ} \mathrm{C}$ & $3.26-3.30$ \\
\hline Silicon Carbide & $\mathrm{SiC}$ & $60-200 @ 25^{\circ} \mathrm{C}$ & $20-33 @ 600^{\circ} \mathrm{C}$ & 3.21 \\
\hline Boron Carbide & $\mathrm{B} 4 \mathrm{C}$ & $45-90 @ 25^{\circ} \mathrm{C}$ & $15.9 @ 700^{\circ} \mathrm{C}$ & $2.48-2.5$ \\
\hline Silicon Nitride & Si3N4 & $14-42 @ 25^{\circ} \mathrm{C}$ & $15.8 @ 1000^{\circ} \mathrm{C}$ & 3.18 \\
\hline Magnesium Oxide & $\mathrm{MgO}$ & $30 @ 125^{\circ} \mathrm{C}$ & $10-12 @ 800^{\circ} \mathrm{C}$ & 3.58 \\
\hline Aluminum Oxide & $\mathrm{A} 12 \mathrm{O} 3$ & $31-35 @ 25^{\circ} \mathrm{C}$ & $\begin{array}{l}8.78-9.2 @ 600^{\circ} \mathrm{C} / 6 @ \\
1300^{\circ} \mathrm{C}\end{array}$ & $3.97-3.98$ \\
\hline Spinel & $\mathrm{MgAl} 2 \mathrm{O} 4$ & $15 @ 25^{\circ} \mathrm{C}$ & $?$ & 3.6 \\
\hline Zirconia & $\mathrm{ZrO} 2$ & $2.7 @ 25^{\circ} \mathrm{C}$ & $1.5-1.6 @ 800^{\circ} \mathrm{C}$ & $4.3-4.6$ \\
\hline Aluminum Titanate & Al2TiO5 & $<2 @ 25^{\circ} \mathrm{C}$ & $\angle 2 @ 1000^{\circ} \mathrm{C}$ & $3-3.4$ \\
\hline
\end{tabular}

Table 7.1: Candidate Material Properties. 


\subsection{Materials Compatibility Studies}

Materials with the highest thermo conductivity at elevated temperature were chosen for testing. Five candidate materials (aluminum nitride, silicon nitride, silicon carbide, titanium diboride and boron nitride) were tested at four temperatures $\left(660^{\circ} \mathrm{C}, 700^{\circ} \mathrm{C}, 800^{\circ} \mathrm{C}\right.$, and $\left.900^{\circ} \mathrm{C}\right)$ for $30-60$ minutes to determine their compatibility with molten aluminum. Experiments were conducted in an electrically heated furnace in a 3" alumina crucible. Samples were cut into rods or disks and placed in the drossed melt. 5052 alloy was used, an alloy known to generate large amounts of dross. We quickly learned that molten aluminum coats and tends to encapsulate everything. This is partly due to the samples being colder than the melt temperature when they were immersed, but also due to the wetting nature of some of the materials. Even after the sample was allowed to reach equilibrium temperature, all of the samples became coated to some degree with aluminum. The boron nitride samples were the only ones where the aluminum was easy to remove upon cooling. In most cases, the metal simply flaked off. The metal was very difficult to remove from the remaining samples. The boron nitride tested was able to withstand temperatures up to $800^{\circ} \mathrm{C}$, at $900^{\circ} \mathrm{C}$ the sample began to degrade. The grade of boron nitride used was HP grade, which used calcium borate as a binder. The calcium borate degrades at $850^{\circ} \mathrm{C}$. There are 3 additional grades of boron nitride commercially available, Grade A, AX05 and ZSBN. Grade A uses boric oxide as a binder, AX05 is self bonded and ZSBN is reaction bonded. A specific capability study was performed to look specifically at various grades of boron nitride.

The melting point of the binder in Grade A boron nitride was only $550^{\circ} \mathrm{C}$, therefore it was not included in the study. The remaining 3 grades of boron nitride were tested in a similar manner to the initial samples. Grade ZSBN behaved comparable to grade $\mathrm{HP}$ as it degraded as the temperature reached $900^{\circ} \mathrm{C}$. Grade AX05 withstood $900^{\circ} \mathrm{C}$ and $1000^{\circ} \mathrm{C}$ temperatures with no degradation. An additional 24 hour test of a grade AX05 sample at $900^{\circ} \mathrm{C}$ yielded results indicating the material could withstand contact with molten metals at elevated temperatures for extended periods of time. This material was chosen to be further investigated as a potential cover of a molten aluminum melt. (Table 7.2)

\begin{tabular}{|c|c|c|c|c|}
\hline & $660^{\circ} \mathrm{C}$ & $700^{\circ} \mathrm{C}$ & $800^{\circ} \mathrm{C}$ & $900^{\circ} \mathrm{C}$ \\
\hline TiB2 & Sample cracked & $\begin{array}{l}\text { Sample coated } \\
\text { Difficult to } \\
\text { remove }\end{array}$ & $\begin{array}{l}\text { Sample coated } \\
\text { Difficult to } \\
\text { remove }\end{array}$ & $\begin{array}{l}\text { Sample wet } \\
\text { Impossible to } \\
\text { remove }\end{array}$ \\
\hline $\begin{array}{l}\text { BN } \\
\text { (grade HP) }\end{array}$ & $\begin{array}{l}\text { Sample coated } \\
\text { Easy to remove }\end{array}$ & $\begin{array}{l}\text { Sample coated } \\
\text { Easy to remove }\end{array}$ & $\begin{array}{l}\text { Sample coated } \\
\text { Easy to remove }\end{array}$ & $\begin{array}{l}\text { Sample coated } \\
\text { Sample began to } \\
\text { degrade }\end{array}$ \\
\hline$\overline{\mathrm{AlN}}$ & $\begin{array}{l}\text { Sample coated } \\
\text { Somewhat easy } \\
\text { to remove }\end{array}$ & $\begin{array}{l}\text { Sample coated } \\
\text { Difficult to } \\
\text { remove }\end{array}$ & $\begin{array}{l}\text { Sample coated } \\
\text { Difficult to } \\
\text { remove }\end{array}$ & $\begin{array}{l}\text { Sample coated } \\
\text { Very difficult to } \\
\text { remove }\end{array}$ \\
\hline $\mathrm{SiC}$ & $\begin{array}{l}\text { Sample coated } \\
\text { Somewhat easy } \\
\text { to remove }\end{array}$ & $\begin{array}{l}\text { Sample coated } \\
\text { Difficult to } \\
\text { remove }\end{array}$ & $\begin{array}{l}\text { Sample coated } \\
\text { Difficult to } \\
\text { remove }\end{array}$ & $\begin{array}{l}\text { Sample coated } \\
\text { Very difficult to } \\
\text { remove }\end{array}$ \\
\hline $\mathrm{SiN}$ & $\begin{array}{l}\text { Sample coated } \\
\text { Somewhat easy } \\
\text { to remove }\end{array}$ & $\begin{array}{l}\text { Sample coated } \\
\text { Difficult to } \\
\text { remove }\end{array}$ & $\begin{array}{l}\text { Sample coated } \\
\text { Difficult to } \\
\text { remove }\end{array}$ & $\begin{array}{l}\text { Sample coated } \\
\text { Very difficult to } \\
\text { remove }\end{array}$ \\
\hline
\end{tabular}

Table 7.2: Summary of Primary Compatibility Study. 


\subsection{Experimental Studies - Argonne}

12 " x 10" x 1/4" plates of grade AX05 boron nitride were obtained from Saint Gobian. 7" x 3" alumina crucibles were used to contain the melt. The initial concept was to determine dross growth using before and after weights, collecting and dross that formed during melting. This proved to be not very accurate due to the amount of dross that would attach to the drossing tools and could not be measured. An online weighting system was developed to allow real time weight measurement of the melt while in the furnace. The design of the system was simple; an inconel plate was attached to an inconel rod that exited the bottom of the furnace. This rod was attached to an aluminum plate that rested on a Mettler-Toledo balance. The balance sent weight measurements to a computer which recorded the data. The balance was able to be tarred after drossing, allowing accurate, real time measurements of the dross generation (Fig 7.1).

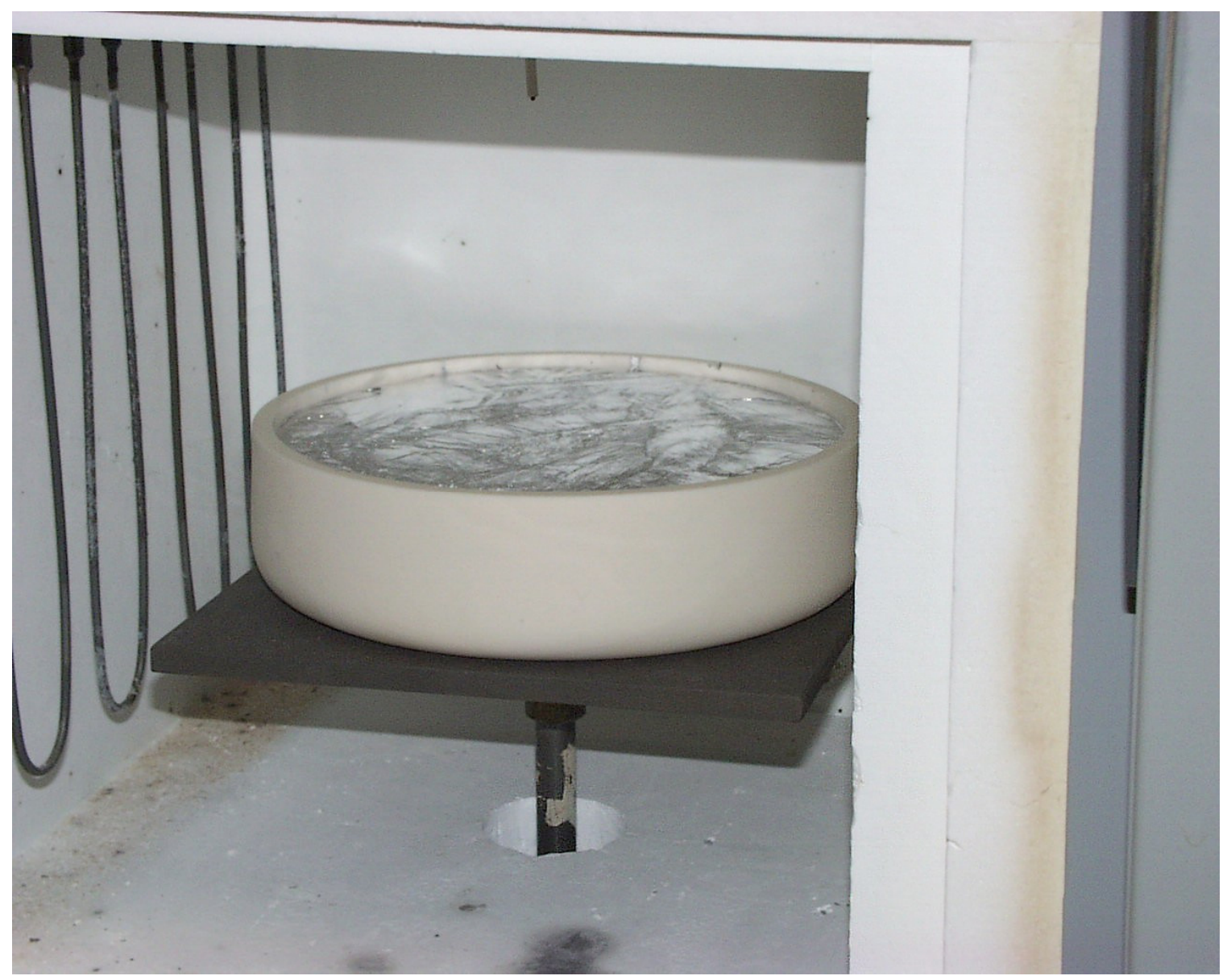

Fig 7.1: Photograph of experimental set up at Argonne National Laboratory

Four experiments were run, two placing the cover directly on the un-melted material and two placing the cover on a drossed surface. The experiments investigating placing the cover directly on the un-melted surface were run at $700^{\circ} \mathrm{C}$ and at $850^{\circ} \mathrm{C}$. The experiments placing the cover on the drossed surface were run at $750^{\circ} \mathrm{C}$ and at $850^{\circ} \mathrm{C}$.

5182 scalper chips were used for both of the cover on an un-melted surface experiment. While the results initially seemed promising displaying reductions of $56.8 \%$ and $67.7 \%$ after 6 hours at $750^{\circ} \mathrm{C}$ and at $850^{\circ}$ $\mathrm{C}$ respectively reductions of only $13.1 \%$ and $10.7 \%$ resulted after 24 hours. 
This weight gain was probably due to the large amount of air pockets that became trapped under the cover as the material melted. Oxidation continued even though the surface was covered. (Fig 7.2 \& 7.3)

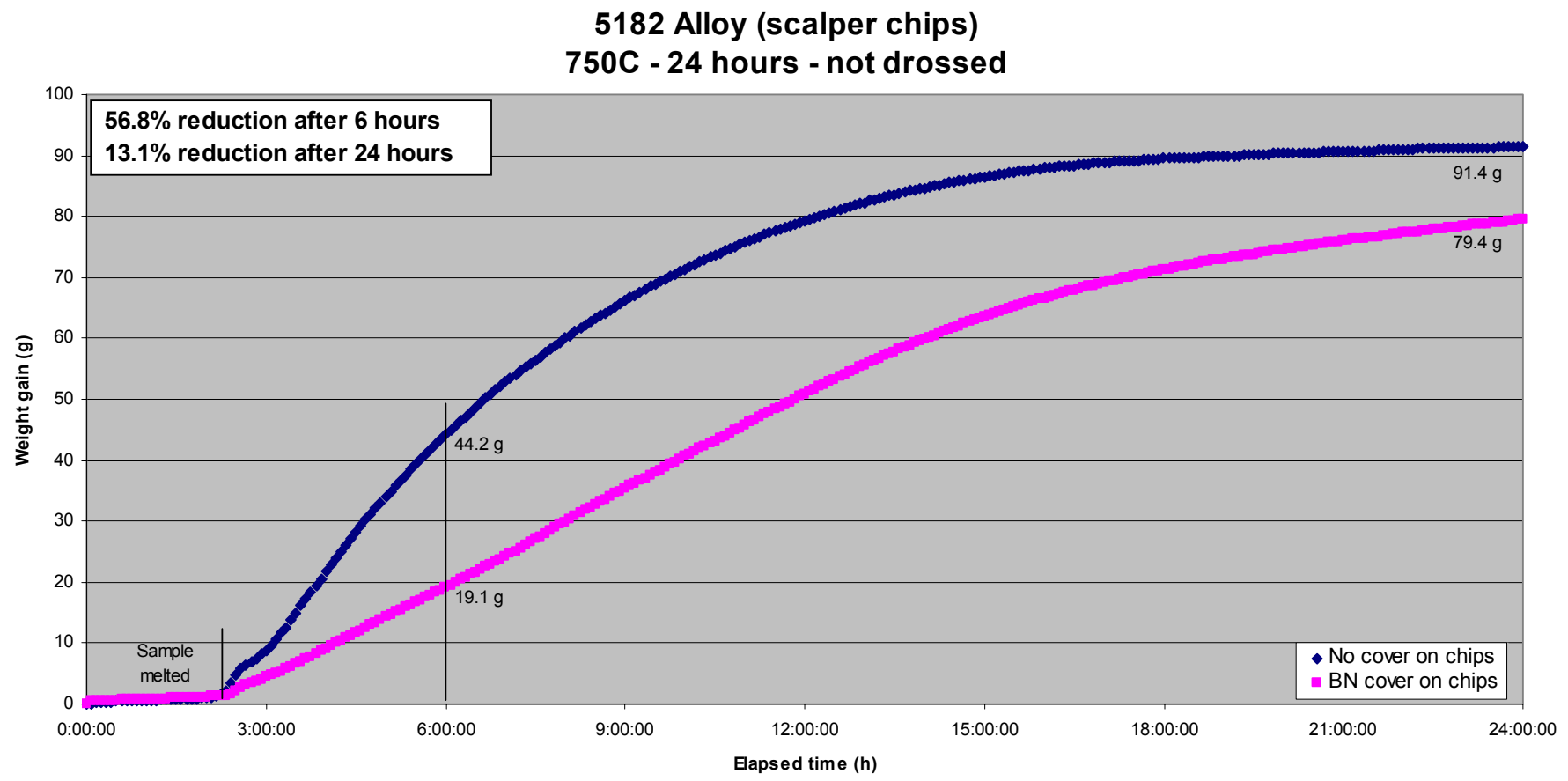

Fig 7.2: 5182 Alloy (scalper chips) 750C -24hrs not drossed

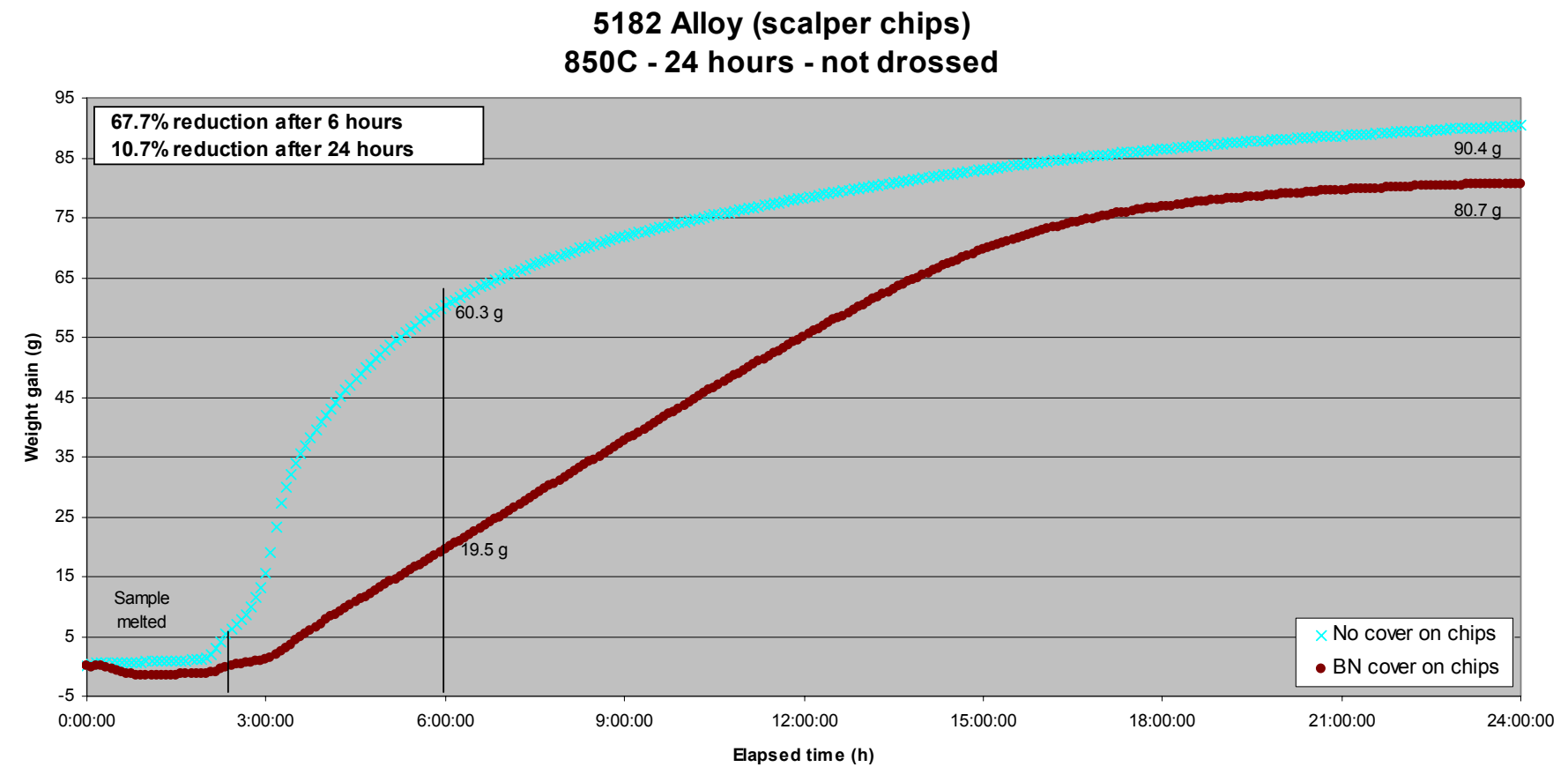

Fig 7.3: 5182 Alloy (scalper chips) 850C 24hrs not drossed 
Alloy 5052 sheet scrap was used for the $700^{\circ} \mathrm{C}$ test and 5182 scalper chips were used for the $850^{\circ} \mathrm{C}$ test, both applying the cover to a drossed surface. Results indicated that after 24 hours dross growth was reduced by $86.5 \%$ for the $700^{\circ} \mathrm{C}$ test and $56.6 \%$ for the $850^{\circ} \mathrm{C}$ test. Both temperature tests also indicate a delay in the onset of dross growth with a 5 hour delay in the $700^{\circ} \mathrm{C}$ test and a 2 hour delay in the $850^{\circ}$ $\mathrm{C}$ test. This delay in the onset of dross growth was not seen in the tests where the plate was placed on the un-melted chips. (Fig $7.4 \& 7.5$ )

\section{Alloy (sheet scrap) \\ 700C - 24 hours - drossed}

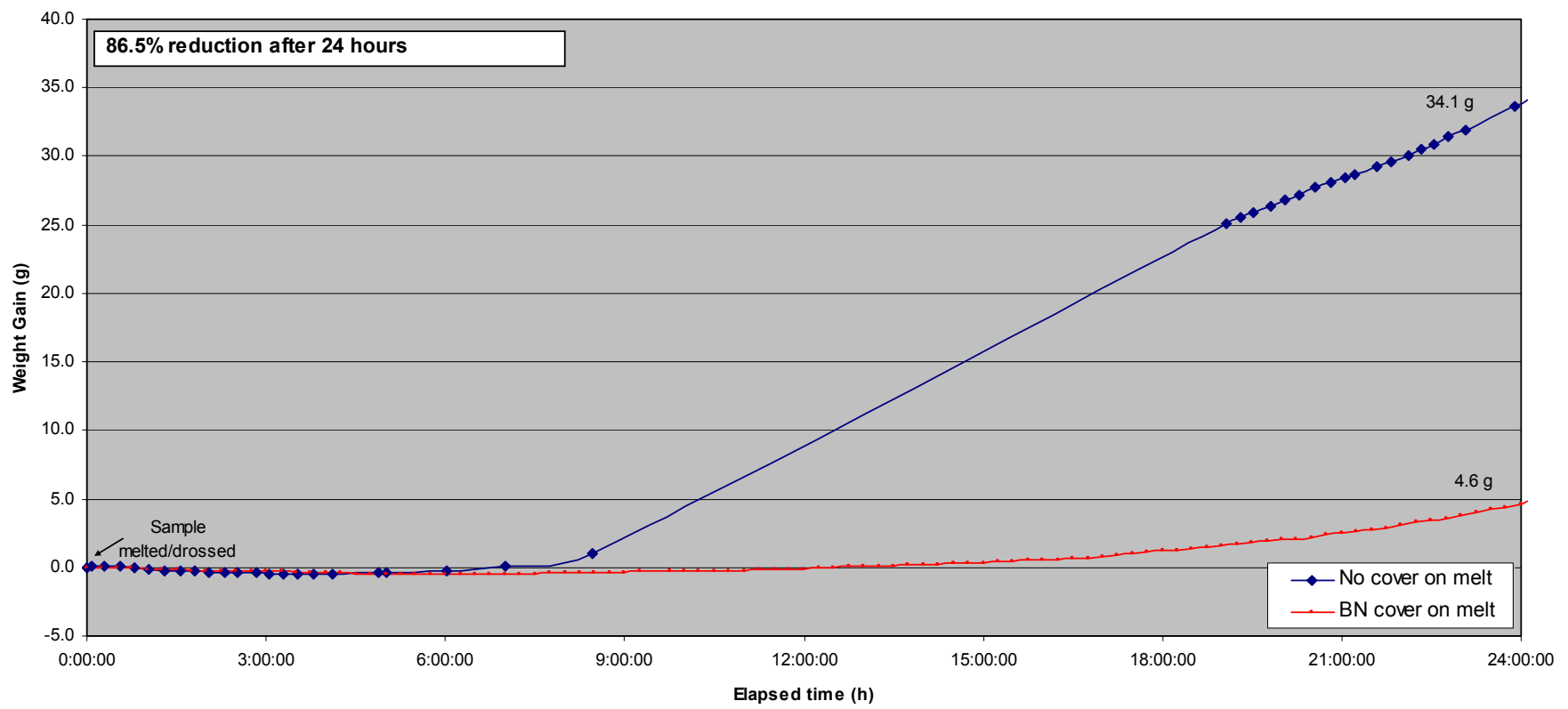

Fig 7.4: 5052 Alloy (sheet scrap) 700C 24hrs - drossed

5182 Alloy (scalper chips)

$850 \mathrm{C}$ - 24 hours - drossed

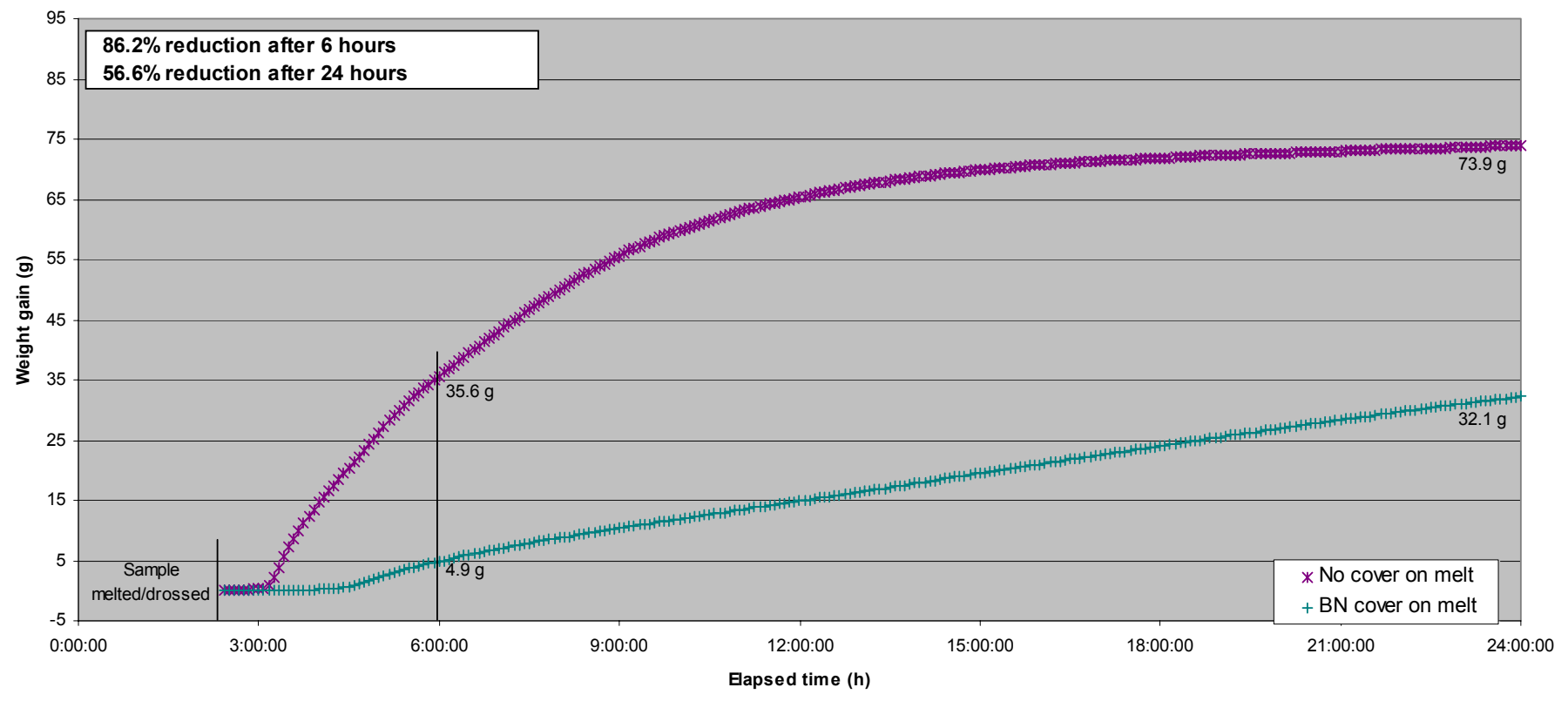

Fig 7.5: 5182 (scalper chips) 850C 24hrs - drossed 
The boron nitride plates were relatively easy to install and remove from the aluminum melts. To facilitate installation and removal, the plates were cut into 4 quadrants. This also allows testing how the cover would perform at the intersections where the covers would meet. From visual inspection, it seems that most of the dross formed at the intersections and around the edges. Small amounts of dross still formed under the cover, but always seemed to have a connection to a seam. Boron analysis of the melt proved to be inconclusive, showing an increase up to $294 \mathrm{ppm}$ in the metal from the non drossed melt. A repeat of this analysis yielded a $135 \mathrm{ppm}$ reading. A sample from a drossed melt yielded $74 \mathrm{ppm}$ boron. Further studies must be done to quantify the boron contamination.

\subsection{Experimental Studies - ARC Reverberatory Furnace}

All experiments carried out at Argonne were done in an electrically heated furnace in air. To determine how the boron nitride plates would withstand an actual furnace atmosphere we ran two tests at Albany Research Center. The experimental set up is shown in Fig 7.6.

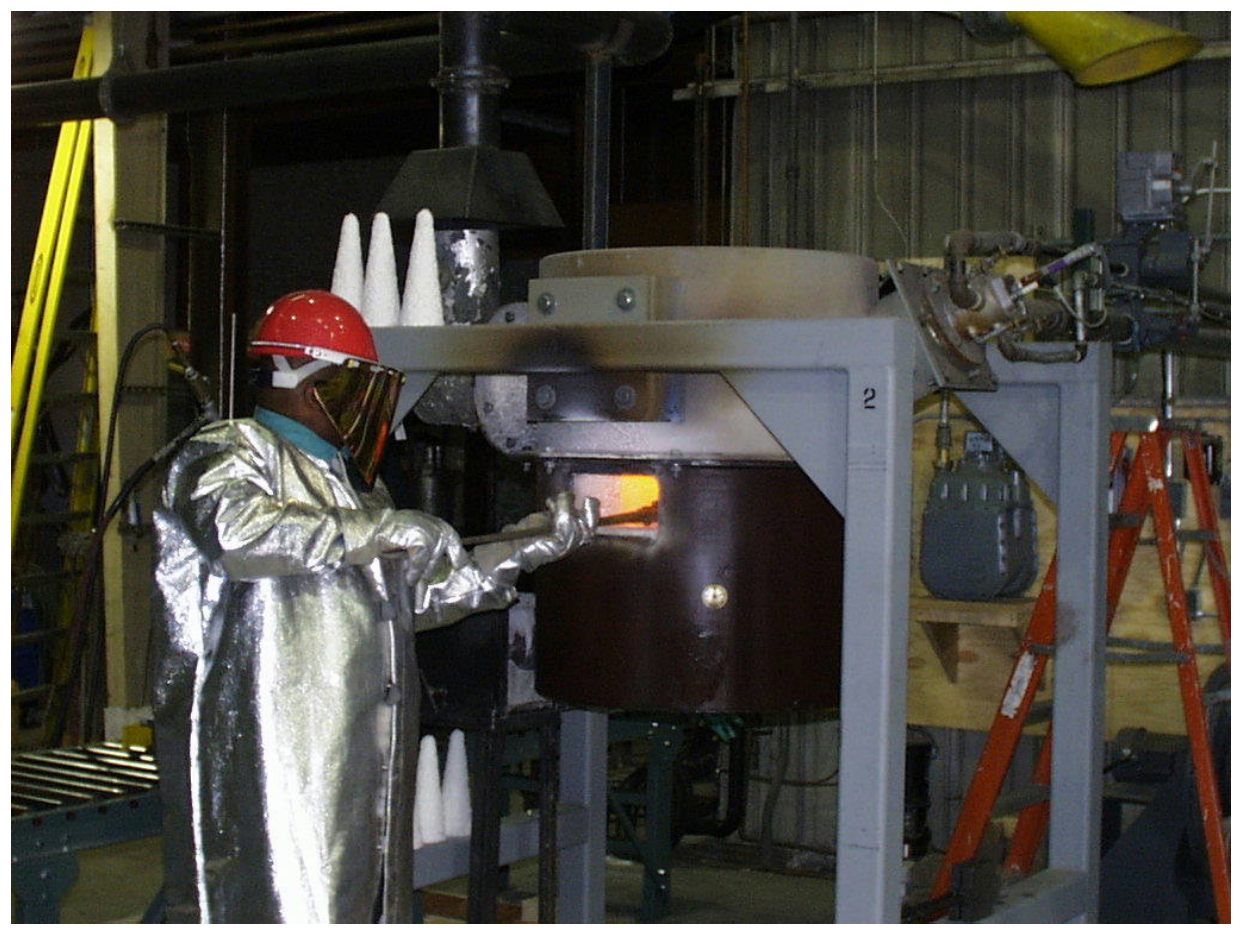

Fig 7.6: Albany Research Center - experimental set up

Both experiments were performed on drossed melts. The first experiment used a 13" crucible with 5182 scalper chips. This took place before an on-line weighing system was installed, so the initial goal was to determine how the boron nitride plates would withstand the gas-fired furnace atmosphere. After 24 hours at $930^{\circ} \mathrm{C}$ the plates were removed. Visually inspecting the plates determined that the material could withstand the furnace environment. The boron nitride plates appeared to have a slight powder coating on them when removed, possibly due to localized over heating of the plate due to the burner. The initial weight of the plates was $1200 \mathrm{~g}$, after 24 hours it was $1195 \mathrm{~g}(+5 \mathrm{~g})$. Dross formed mainly around the edges of the plates and at the seams.

The second experiment used a 13" crucible on an on-line weighing system. This experiment used 5182 edge trim with a furnace temperature of about $870^{\circ} \mathrm{C}$. The boron nitride plate reacted similarly to the first experiment and the dross was mainly on the outer edges between the plates and the crucible edges. After 24 hours there was a $21.5 \%$ weight reduction on the melt with the cover installed. Both graphs 
seemed to trend similarly. It was disappointing not to see a greater reduction in weight gain. Possibly the gaps between the crucible and the edge of the plates were greater than in the Argonne experiments, which allowed for greater dross growth. It also could have been that the melts were not drossed as completely as in the Argonne experiments due to the larger melt size and depth.

\subsection{Summary}

Dross growth can be reduced by the application of a cover on the melt surface. The effectiveness of the cover seems to vary by how complete the coverage is and how well the melt was cleaned prior to the installation of the cover. 


\section{Accomplishments}

\section{1: Technical Accomplishments}

A. Understanding the effects of alloy class, furnace atmosphere and individual alloying elements on dross formation

1. Equipment Development

a. Equipment and method to measure the initial stages of aluminum alloy oxidation using x-ray photoelectron spectroscopy (XPS) at ANL

b. Small high-temperature furnaces used at the Advanced Photon Source for in-situ Xray diffraction (XRD)analysis of an oxidizing molten aluminum alloy surface at ANL

c. Lab-scale furnace with continuous on-line balance to determine small changes in weight during oxidation of bulk aluminum alloys at ANL

d. Lab-scale gas-fired reverberatory furnace to evaluate technologies to minimize melt loss at ARC

2. Technique and Capability Development

a. Method of standardized dross collection from industrial furnaces

b. In-situ characterization of molten aluminum surface(for XPS and XRD)

c. Method for measuring weight change during oxidation of aluminum

3. New Data to Further Understanding of Melt Loss

a. Oxidation mechanisms of industrial dross samples consistent with dross samples generated in the laboratory

- both have layered microstructure

- $\quad$ structures depend on local Mg content at metal-dross interface

- pre-existing oxide affects layering in similar ways

b. Only magnesium segregates to the surface of solid and liquid aluminum alloys

c. First direct observation that crystalline $\mathrm{MgO}$ forms first on molten $\mathrm{Al}-\mathrm{Mg}$ alloys

4. Technology Development

a. Boron nitride as a barrier to metal oxidation

- physical barrier that limits Mg vaporization

- patent issued, contact Secat for licensing

b. Boric acid applied to solid aluminum is not an effective method to reduce dross formation

B. Effect of increase in temperature and holding time on the transition from 2 dimensional to 3 dimensional growth

a. Increase in temperature and holding time increases dross formation

b. Transition from 2 to 3 dimensional growth occurs above a specified temperature

c. Use of surface barriers reduces the melt loss at increased temperatures and holding times

d. Boron Nitride tiles is affective as a barrier 


\section{Develop industrial practices that would reduce melt loss by disseminating the improved fundamental understanding of dross formation to all industry participants.}

a. Dissemination of knowledge and improved understanding of dross formation to all industry participants

b. Improved practices at plants by controlling temperature and holding times to optimum levels

c. Control burner settings to avoid excessively high $\mathrm{O} 2$ levels.

d. Use of Boron Nitride tiles has shown marked decrease in dross formation

e. Discuss the possibility of using Boron nitride tiles at the plant level. At this point of time it is considered costly to use this material

This project succeeded in developing a detailed understanding of the kinetics of dross formation and how the different elements played a key role in the oxidation of aluminum and the formation of dross.

Aluminum alloys with minimum $\mathrm{Mg}$ content had low dross formation levels and by following acceptable process practices the oxidation could be controlled. It became clear during the course of the project that $\mathrm{Mg}$ was the primary element that caused the promotion of oxidative dross and any attempt to suppress the formation of $\mathrm{Mg}$ dross would lead to reduction of dross formation. This led to the identification and development of two potential barriers of which boric acid was a failure and a patent was taken on the use of Boron Nitride.

The detailed understanding of the kinetics of dross formation has permitted industry partners to modify their plant practices to improve recovery rates and reduce dross formation. This has enabled them to improve productivity, reduce melting costs and waste.

It is to be noted here that although technologically Boron Nitride was successful from the economic point of view the industrial partners were unwilling to use it at the time of project completion in their plants. As technology develops in the manufacture of various shapes of Boron Nitride and it moves from a manual production process to a more mechanized process it will be possible to introduce at the plants on a regular basis.

\subsection{Technology Transfer}

The key product of technology transfer that resulted from this project was a patent taken by the Argonne National Laboratory that covers the technology concept of using Boron Nitride that was developed in this project.

In addition, several presentations were made in the US and Europe detailing the findings of this report. The most significant of these was a presentation at a special session of the Mineral, Metals, and Materials Society (TMS) at the Annual Meeting in 2003. The session was attended by representatives of all the major aluminum producers in the U.S. and abroad.

Patent: Hryn, J.N., M.J. Pellin, J.F. Moore, W.F. Calaway, G.K. Krumdick, "Method to Decrease Loss of Aluminum and Magnesium Melts." U.S. Patent No. 6,485,541, issued November 26, 2002. (Contact Secat for licensing)

The knowledge and understanding generated during the course of the project has been disseminated to all industry partners including the development of a laboratory sized facility to carry out melt trials at the Albany research Center as well as development of a sophisticated method for evaluating dross formation at the Argonne National Laboratory using XPS. This is available for future use by industry participants 


\subsection{Commercialization}

Project participants have used several mechanisms to inform industries of the research results and advance commercialization including launching Aluminum Answers, a Secat website, partly for disseminating the latest research results into the aluminum industry, and making presentations at national meetings organized by the Minerals, Metals, and Materials Society (TMS), and the American Society of Metals (ASM), and implementing the results and findings at industrial locations.

The results generated at these sites are considered proprietary. A patent was filed on one covering agent Boron Nitride tiles by Argonne National Laboratory and is available for implementation by industry based on their interest.

\subsection{Publication and Presentations}

As the majority of the work was considered proprietary most of the information was disseminated among industry partners through review meetings and reports. The main publications were

1. A presentation at a special session of the Mineral, Metals, and Materials Society (TMS) at the Annual Meeting in 2003

2. Microstructural Evaluation of dross formation in $\mathrm{Mg}$ and non $-\mathrm{Mg}$ containing alloys from industrial furnaces KL More, P.F Tortorelli, L.R. Walker, J Hryn, and G Krumdick

3. Patent: Hryn, J.N., M.J. Pellin, J.F. Moore, W.F. Calaway, G.K. Krumdick, "Method to Decrease Loss of Aluminum and Magnesium Melts." U.S. Patent No. 6,485,541, issued November 26, 2002. (Contact Secat for licensing) 


\section{Summary and Conclusions}

This project led to an improved understanding of the mechanisms of dross formation. The microstructural evolution in industrial dross samples was determined. Results suggested that dross that forms in layers with structure and composition determined by the local magnesium concentration alone. This finding is supported by fundamental studies of molten metal surfaces. X-ray photoelectron spectroscopy data revealed that only magnesium segregates to the molten aluminum alloy surface and reacts to form a growing oxide layer. X-ray diffraction techniques that were using to investigate an oxidizing molten aluminum alloy surface confirmed for the first time that magnesium oxide is the initial crystalline phase that forms during metal oxidation. The analytical techniques developed in this project are now available to investigate other molten metal surfaces.

Based on the improved understanding of dross initiation, formation and growth, technology was developed to minimize melt loss. The concept is based on covering the molten metal surface with a reusable physical barrier. Tests in a laboratory-scale reverberatory furnace confirmed the results of bench-scale tests.

The main highlights of the work done include:

A clear understanding of the kinetics of dross formation and the effect of different alloying elements on dross formation was obtained. It was determined that the dross evolves in similar ways regardless of the aluminum alloy being melted and the results showed that amorphous aluminum nitride forms first, followed by amorphous magnesium oxide and crystalline magnesium oxide in all alloys that contain magnesium. Evaluation of the molten aluminum alloy surface during melting and holding indicated that magnesium oxide is the first crystalline phase to form during oxidation of a clean aluminum alloy surface. Based on dross evaluation and melt tests it became clear that the major contributing factor to aluminum alloy dross was in the alloys with $\mathrm{Mg}$ content.

$\mathrm{Mg}$ was identified as the primary factor that accelerates dross formation specifically in the transition from two phases to three phase growth. Limiting magnesium oxidation on the surface of molten aluminum therefore becomes the key to minimizing melt loss, and technology was developed to prevent magnesium oxidation on the aluminum surface. This resulted in a lot of the work being focused on the control of $\mathrm{Mg}$ oxidation.

Two potential molten metal covering agents that could inhibit dross formation during melting and holding consisting of boric acid and boron nitride were identified. The latter was discounted by industry as it resulted in Boron pick up by the melt beyond that allowed by specifications during plant trials.

The understanding of the kinetics of dross formation by the industry partners helped them understand how temperature, alloy chemistry and furnace atmosphere (burner controls- e.g. excess air) effected dross formation. This enables them to introduce in their plant process changes that reduced unnecessary holding at high temperatures, control burner configurations, reduce door openings to avoid ingress of air and optimize charge mixes to ensure rapid melting and avoid excess oxidation.

\section{Recommendations}

This research project has successfully demonstrated that an increased understanding of the kinetics of dross formation and its behavior can lead to better controls within the plant to reduce dross and improve efficiencies. It would be good to perhaps develop some computational tools that would enable prediction of dross formation based on alloy chemistry, temperature of operation and protective covers. 


\section{References}

1. C.J. Moser, "Furnace Dross - Its Formation and Recovery," Light Metals 1976, 299-311 (1976).

2. S. Freti, J.D. Bornand and K. Buxmann, "Metallurgy of Dross Formation on Al Melts," Light Metals 1982, 1003-1016 (1982).

3. R.D. Peterson and A. Revet, "Dross Analysis Methods and Their Application for Evaluating Secondary Furnace Operations," Recycling of Metals and Engineered Materials, eds., D.L. Stewart, Jr., J.C. Daley, and R.L. Stephens, TMS, 1035-1044 (2000).

4. H. Rossel, "Fundamental Investigations About Metal Loss During Remelting of Extrusion and Rolling Fabrication Scrap,” Light Metals 1990, ed. C.M. Bickert, TMS, $721-729$ (1990),

5. SECAT Press Release.

6. D.A. Wenz, "Laboratory investigation of Skim Formation in Aluminum Melting," Light Metals 1979, TMS, 771-780 (1979).

7. J.H.L. van Linden and H.G. Reavis, "Melt Loss Evaluation," Light Metal 1986, TMS, 785-792 (1986).

8. S. Impey, D.J. Stephenson, and J.R. Nicholls, "A Study of the Effect of Mg Additions on the Oxide Growth Morphologies on Liquid Al Alloys," in Microscopy of Oxidation I, eds., G. Tatlock and S. Neucomb, Science Reviews, 238-244, (1991).

9. S. impey, D.J. Stephenson, and J.R. Nicholls, "The Influence of Surface Preparation and Pretreatments on the Oxidation of Liquid Al and Al-Mg Alloys," in Microscopy of Oxidation II, eds. G. Tatlock and S. Neucomb, Science Reviews, 323-337 (1993).

10. C.N. Cochran, D.L. Belitskus, and D.L. Kinosz, "Oxidation of Al-Mg Melts in Air, Oxygen, Flue Gas, and Carbon Dioxide," Met. Trans. B, 8B, 323-332 (1977).

11. W.R. Ford and N. Christ, "A Study of the Formation and Behavior of Al Skim," Light Metals 1974, TMS, 639-648 (1974).

12. O. Manfredi, W. Wuth, and I. Bohlinger, "Characterizing the Physical and Chemical Properties of Al Dross," JOM, Nov. 1997, 48-51 (1997).

13. The Aluminum Association, Aluminum Industry Technology Roadmap, 1997

14. D. L. Stewart, Jr., "Aluminum Melting Technology - Current Trends and Future Technology," Light Metals 2002, pp. $719-724$

15. Frank L. Beichner, "Efficiency Evaluation of Melting Aluminum Furnaces," Light Metals 2002, pp. $725-730$

16. Rifat Alchalabi and Fanli Meng, "Furnace Operation Optimization Via Enhances Bath Circulation," Light Metals 2002, pp. 739 - 746

17. C. N. Cochran, D. L. Belitskas, D. L. Kinosz, "Oxidation of Aluminum-Magnesium Melts in Air," Metallurgical Transactions, 1977, vol. 8B, pp. $203-217$

18. Justin Teiken and Leonard Krietz, "Additive Effects on the Physical Properties of Castable Systems for Aluminum Contact Applications," The $9^{\text {th }}$ Symposium on Refractories for the Aluminum Industry, George Oprea, ed., TMS, 2000, pp. 5 - 21

19. Wesley Stevens and Jean-Yves Fortin, "Development of a Pilot 'Top Charge' Melt Furnace to Examine Fundamental Melting Phenomena in Aluminum," Light Metals 2002, pp. 747 - 750

20. John A.Clark, III, "The ARC Laboratory Scale Reverberatory Furnace for Secondary Aluminum Melting - A Unique Resource," Poster Presentation at the 2002 Annual Meeting of The Minerals, Metals, \& Materials Society, Seattle, WA, February 17 - 21, 2002. 